Article

\title{
Sustainable Drinking Bars in China: Evidence, Initiatives, and Guidelines Based on the 2030 Agenda
}

\section{Yuanbo Li}

School of Public Policy and Management, Institute for Sustainable Development Goals, Tsinghua University, Beijing 100084, China; lyb18@tsinghua.org.cn

Received: 3 December 2019; Accepted: 3 January 2020; Published: 7 January 2020

Abstract: China is a fascinating market in terms of alcohol consumption. Although drinking bars originated in the West, economic and societal developments have spread the concept throughout China. In 2017, there were approximately 59,600 drinking bars in China, with a 44.06 billion RMB market size. Given societal development, the Chinese bar industry has gradually paid attention to environmental protection and sustainable development. A sustainable bar adopts a management model that reduces and recycles waste and saves energy. The social responsibility of bars is reflected in sustainable consumption. The concept of sustainable bars has been well-received worldwide. The 2030 Agenda for Sustainable Development (2030 Agenda) provides direction on sustainable development to relevant stakeholders. The 2030 Agenda contains 17 interactive Sustainable Development Goals (SDGs), including the SDG12. Thus, it is important to explore the development of Chinese sustainable bars under the 2030 Agenda and the 17 SDGs. Hence, the Institute for Sustainable Development Goals (TUSDG) of Tsinghua University, Pernod Ricard China, and Kantar China organized one tripartite research group and conducted investigations on drinking bars from three megacities (Shanghai, Shenzhen, and Beijing) to explore the situation, recognition, perspectives, and actions of sustainable bars in China. The results have significant implications. Moreover, the three parties jointly released the "Sustainable Bar Operation Initiatives" and the "Operational Sustainable Bar Application Guidelines" for the bar industry in China.

Keywords: China; drinking bars; 2030 Agenda; Sustainable Development Goals (SDGs); initiatives and guidelines

\section{Introduction}

Sustainable development refers to a combination of the sustainability of economic and societal development, as well as sustainable resources and the environment on which the economic society depends. To summarize the implementation of the Millennium Development Goals (MDGs) from 2000 to 2015, in September 2015, state leaders adopted the document "Transforming Our World: The 2030 Agenda for Sustainable Development" (The 2030 agenda) at the United Nations Sustainable Development Summit, as well as the 17 Sustainable Development Goals (SDGs) [1]. Currently, there is a worldwide consensus on the Post-2015 development agenda regarding sustainable development. The international community and China attach great importance to the 2030 Agenda, which contains 17 interrelated SDGs. SDGs include 17 goals as follows. SDG1: No poverty. SDG2: Zero Hunger. SDG3: Good health and well-being. SDG4: Quality education. SDG5: Gender equality. SDG6: Clean water and sanitation. SDG7: Affordable and clean energy. SDG8: Decent work and economic growth. SDG9: Industry, innovation, and infrastructure. SDG10: Reduced inequalities. SDG11: Sustainable cities and communities. SDG12: Responsible consumption and production. SDG13: Climate action. SDG14: Life below water. SDG15: Life on land. SDG16: Peace, justice, and strong institutions. SDG17: Partnerships for the goals. Overall, the SDGs have 169 targets and 232 indicators [2]. It is worth 
noting that the 17 SDGs are interrelated and indispensable, combining three factors of sustainable development (economic, social, and environmental) and five dimensions (people, planet, prosperity, peace, and partnership) [3].

The sustainability of services and consumption is also part of the 2030 Agenda, mainly reflected in the Goal 12 "Ensure sustainable consumption and production patterns". The first use of the term "sustainable consumption and production" was by the Oslo Symposium in 1994, where sustainable consumption and production (SCP) is posed as "the use of services and related products which respond to basic needs and bring a better quality of life while minimizing the use of natural resources and toxic materials as well as the emissions of waste and pollutants over the life cycle of the service or product so as not to jeopardize the needs of further generations" [4]. The revised UN Guidelines for Consumer Protection in 2015, based on the first adopted version in 1985 and the expanded version in 1999, encourage Member States, relevant organizations, groups, business, and civil society to promote sustainable consumption, which has been listed in the objectives of guidelines [5]. In 2012, during the United Nations Conference on Sustainable Development (Rio+20), it adopted a global framework for SCP- the 10-Year Framework of Programmes on Sustainable Consumption and Production Patterns (10YFP) for transforming consumption into SCP in both developing and developed countries [6]. SCP became the cornerstone of the SDG12 in 2015 and one driving norm for both production and consumption globally [7]. For SCP in the 2030 Agenda since 2015, current SDG12 in 2019 contains 11 targets and 13 indicators [8]. Target 12.3 of SDG12 states that "By 2030, halve per capita global food waste at the retail and consumer levels and reduce food losses along production and supply chains, including post-harvest losses". Its corresponding indicator, 12.3.1, is the "(a) Food Loss Index and (b) food waste index". Target 12.5 states that "By 2030, substantially reduce waste generation through prevention, reduction, recycling, and reuse". Its corresponding indicator, 12.5.1, is the "national recycling rate [and] tons of material recycled". Target 12.6 states that "Encourage companies, especially large and transnational companies, to adopt sustainable practices and to integrate sustainability information into their reporting cycle". Its corresponding indicator, 12.6.1, is the "Number of companies publishing sustainability reports". Moreover, SDG12 is closely related to the other SDGs [3]. SCP is also important for China, which is the largest developing country in terms of territory, population, economy and market size. China has achieved great progress in economic and social development during the past three decades with expanding market size and attractive market opportunities for companies. After achieving world-renowned economic achievements, China begins to reflect on environmental issues and costs. For SCP at the national level, on one hand for sustainable production, there is the adjustment of industry structure, promotion of a circular economy and cleaner production, energy conservation and emission reduction. On the other hand, for sustainable consumption, there are eco-labelling, green procurement, and the promotion of waste management in China [9]. For sustainable consumption and the circular economy in China, recently, various research papers related to green economy and consumption and low-carbon consumption have been published [10]. However, approaches from government system in China for SCP are thought to be insufficient while significant changes in consumption patterns occur for large and rapid urbanization [11]. Challenges or barriers for SCP in China may include the extensive growth model, regional development inequality, technology and innovation capacity, underdevelopment of NGOs, poor regulation and practices, financial mechanisms, markets, culture, and information $[9,10]$.

The participation of private enterprises and consumers is also crucial to sustainable development and SDGs, which includes SDG12 and SCP, in the world and in China. There are already several existing studies in China for SCP at national and macro-level. Hence, this study begins at a micro and new aspect, taking the drinking bar industry as one example to explore sustainable development and SDGs in China. Given the rapid development of China's drinking bar industry and the environment-protection awareness of consumers, the development of sustainable bars is trending both abroad and inside China. To understand the development of Chinese sustainable bars and the response of Chinese bars to sustainable development and SDGs, from March to May 2019, the Institute for Sustainable 
Development Goals (TUSDG) of Tsinghua University, the Pernod Ricard China, a French world-class alcoholic beverages company, and the Kantar China, an UK world-class consulting company, jointly completed a qualitative and quantitative survey and a workshop on the development of Chinese sustainable bars based on the 2030 Agenda for Sustainable Development.

Thus, this study has four main goals:

1. To understand the current situation of the drinking bar industry in China and sustainable bars worldwide.

2. To understand how Chinese drinking bar operators manage their bars with respect to sustainable development, what specific actions and measures are in place, and what can be done in the future.

3. To investigate how Chinese drinking bar practitioners and operators view the UN 2030 agenda and the 17 SDGs, as well as how sustainable bars in China can contribute to achieving such agenda and goals.

4. To evaluate the opinions of practitioners and operators of drinking bars in China regarding the results obtained and draft operational guidelines for sustainable bars in China in the context of the 2030 Agenda based on the results and analyses.

\section{Materials and Methods}

To achieve these goals, the Institute for Sustainable Development Goals (TUSDG) of Tsinghua University, Pernod Ricard China, and Kantar China co-organized one tripartite research group and conducted several investigations as follows. First, desk research for the development of drinking bars in China and the development of sustainable bars worldwide was initiated. Second, a qualitative survey involving 15 face-to-face interviews of drinking bar owners or managers in three big Chinese cities (Shanghai, Shenzhen, and Beijing; five drinking bars each city) was conducted. Third, based on the results and analysis of the surveys and qualitative interviews, a quantitative research by 321 questionnaires of drinking bar practitioners and operators in Shanghai (114), Shenzhen (105), and Beijing (102) has been finished on-line. The qualitative and quantitative survey mainly consists of three parts: first, how Chinese bar owners can manage bars towards sustainable development and what specific actions and measures they have; second, what criteria Chinese bar owners think sustainable bars can have; third, how Chinese bar owners view the 2030 Agenda, the 17 SDGs, and their relationship with the sustainable development of Chinese bars. Fourth, based on the results, drafts are prepared for initiatives and guidelines for sustainable bars in China, and a workshop for discussion by invited practitioners and operators of drinking bars in China has been conducted. Finally, the three aforementioned organizations jointly released the "Sustainable Bar Operation Initiatives" and the "Operational Sustainable Bar Application Guidelines" for the bar industry in China.

\section{Results and Discussion}

\subsection{Drinking Bar Industry in China and Sustainable Bars Worldwide}

Currently, China is a super attractive market for alcohol consumption, and this is improving with social and economic living conditions. Drinking plays a significant role in social and daily activities, such as festivals, ceremonies, parties, networking, and business in China [12]. In 2018, the volume of alcoholic drinks in China is estimated to be 42,662 million liters of beer, 13,627 million liters of spirits, 1,667 million liters of wine, and 2,748 million liters of cider, perry, and rice wine, thereby making China the second-largest market for alcohol in the world after the USA [13]. Considering wine consumption, traditional alcohol, such as Baijiu (liquor from cereals), occupies the traditional alcohol market in China; however, Chinese people began to learn more about grape wines in the past decade [14]. Regarding wine consumption, China has been one of the largest wine markets with 17.6 million hectoliters of consumption and 6.9 million hectoliters of imports in 2018, making China the $5^{\text {th }}$ largest consumer in the world [15]. This situation is due to economic growth and consumers' interests in Western wine and wine culture [16]. Growing wine consumption also contributes to domestic wine production. The majority of 
wines consumed in China are produced domestically, and China has the world's second-largest vineyard, among which only $10 \%$ is used for grape wine, with potential for growth in the future [17].

Given the rapidly growing demand for alcohol consumption and drinking bars, numerous distinctive drinking bars have emerged throughout China. The drinking bar originated in Europe and America; it was introduced into China in 1980 after the Reform and Opening Up. With the development of the economy, society, and culture, bars have become ubiquitous in China. In 2017, China had about 59,600 bars, and the market size of the Chinese bar industry was about 44.06 billion yuan [18]. In terms of quantity and distribution, Chinese bars are mainly distributed in economically developed and densely populated areas or tourism cities. Bars are mainly distributed around the Bohai region of Beijing and Tianjin, the Yangtze River Delta region (represented by Shanghai and Zhejiang), the Pearl River Delta region (represented by Shenzhen and Guangzhou), and the southwest region (represented by Chengdu, Kunming, and Chongqing), as well as some tourism cities like Lijiang and Yangshuo. Concerning consumers, regular consumers are white-collar workers, businessmen, and young people. A bar is a place of business, social activities, and leisure, which can be divided into different types of bar cultures due to the differences in factors, such as consumer groups, locations, positioning, themes, and types of catering.

With the development of society and the improvement of the quality of consumers, especially among young consumers, the concept of corporate social responsibility, such as environmental protection and sustainable development, has gradually found its way into the bar industry. The sustainable bar has a bar management mode that reduces waste emissions, saves energy, advocates recycling, and focuses on harmonious coexistence with the community in which it is located. It can include actions such as avoiding the use of plastic products, making full use of food materials to reduce waste, and reducing energy consumption, thus reflecting the bar's corporate social responsibility in areas such as sustainable operation and sustainable consumption. From a broad practical point of view, the practice of sustainable bars includes bars that are decorated with recycled materials and bartending materials that are mostly local, organic, and seasonal materials, thus reducing transportation costs and energy consumption. The practice also allows local people to think about the relationship between humans and nature; save water for consumption, ice, and electricity during bartending; replace plastic products, such as straws and coasters, with recyclable materials, such as glass and paper; prolong the probation period of raw materials; and recycle waste materials. This situation enables customers to understand the importance of the bartending process and the sustainability behind it and to pay attention to the evolution of food materials from "fields to tables" and the environmental impact of the evolution, thus avoiding wasting raw materials and reducing excessive consumption. The concept of sustainable bars has received worldwide attention. Many bars have created different sustainable management methods relative to their local characteristics. Several bars on the 10th World's 50 Best Bars published in 2018, as well as the 2018 Asia's 50 Best Bars list, combine the concept of sustainable development with the management of bars [19].

\subsection{Qualitative Interviews and Results}

This qualitative survey of the tripartite research group was conducted in three big cities -Shanghai, Shenzhen and Beijing, which are three megacities with a large population and economic scale and numerous bars in mainland China. In each city, with the aid of the social and business networks of Pernod Ricard China, we selected five bars (in total 15 bars in three cities) to conduct 15 face-to-face interviews with bar owners or managers (one person interviewed per bar) and surveys on Chinese bars and sustainable development, especially regarding the 2030 Agenda and the SDGs. The 15 bars include two whiskey bars, two restaurant bars, four cocktail bars/speakeasy/hidden bars, a big scale high energy bar, three lounge/hotel lounges, a pub/dive bar, a whiskey cocktail bar, and a wine bar to ensure its variety, as shown in Table 1 . The 15 interviewees (owner or manager) interviewed from 15 bars must have at least six years of experience in the bar industry, must have worked in the bar they currently work in for at least two years and be responsible for the operation and management of the bar, and must have some knowledge and behaviors related to sustainable development in bar 
operations. During the interviews, the interviewers from the tripartite research group firstly presented the background and goals of research and conducted interviews through dialogue and questions. The interview conversations were conducted in Chinese if the owner or manager can speak it or in English. The main content and questions of the interviews to 15 interviewees were divided into three parts: First, how do 15 interviewees manage their bars sustainably, and what specific actions and measures have they taken? Second, what criteria do 15 interviewees think that sustainable bars in China should have? Third, how do 15 interviewees view the 2030 Agenda and the 17 SDGs, and what can be done in Chinese drinking bars based on this agenda and sustainable development goals? The whole conversations of 15 interviews were noted and recorded as shown in Table 1.

Table 1. 15 surveyed drinking bars in Shanghai, Shenzhen, and Beijing.

\begin{tabular}{|c|c|c|c|c|}
\hline City & Code & Type of Bar & Recording Duration & Interview Language \\
\hline \multirow{5}{*}{ Shanghai } & A1 & whiskey bar & 1:16:09 & Chinese \\
\hline & A2 & restaurant bar & 1:22:30 & Chinese \\
\hline & $\mathrm{A} 3$ & cocktail bar/speakeasy/hidden bar & 33:37 & Chinese \\
\hline & A4 & big scale high energy bars & 1:11:34 & English \\
\hline & A5 & lounge/hotel lounge & $1: 16: 44$ & English \\
\hline \multirow{5}{*}{ Shenzhen } & B1 & lounge/hotel lounge & 1:28:17 & Chinese \\
\hline & B2 & cocktail bar/speakeasy/hidden bar & 1:30:30 & English \\
\hline & B3 & pub/dive bar & 1:19:44 & Chinese \\
\hline & B4 & restaurant bar & $1: 35: 22$ & Chinese \\
\hline & B5 & whiskey bar & 1:28:00 & Chinese \\
\hline \multirow{5}{*}{ Beijing } & $\mathrm{C} 1$ & cocktail bar/speakeasy/hidden bar & $1: 19: 22$ & Chinese \\
\hline & $\mathrm{C} 2$ & whiskey cocktail bar & $43: 54$ & Chinese \\
\hline & $\mathrm{C} 3$ & cocktail bar/speakeasy/hidden bar & $58: 35$ & English \\
\hline & $\mathrm{C} 4$ & lounge/hotel lounge & $1: 33: 23$ & English \\
\hline & $\mathrm{C} 5$ & wine bar & $47: 27$ & Chinese \\
\hline
\end{tabular}

For the previous three questions in qualitative interviews, the results of the qualitative interviews show that first the concept and practice of sustainable development and SCP have also been recognized and reflected in the management of many bars. Second, different bars have their own practice of sustainable development and SCP. Bar operators express recognition on the importance of sustainable development of bars and are willing to make efforts and suggest sustainable development practices for their own bars and the bar industry in China. Third, the qualitative interview results show that, although the bar operators' knowledge on the 2030 Agenda and the 17 SDGs is limited, they are taking and will take many concrete sustainable actions in bar operation, which are closely connected with the 2030 Agenda and 17 SDGs. After conducting 15 interviews and collecting the information and data from notes and records, the tripartite research group analyzed and classified 15 interviewees' perception, specific actions and future suggestions for their bars, sustainable drinking bars in China and the 2030 Agenda into 17 Sustainable Development Goals (SDGs) as in Table 2. In total, the tripartite research group produced 32 items about bar operators' perception, 49 items about specific actions of bars, and 35 items about future suggestions for sustainable bars in China, as presented in Table 2. According to the results of interviews of 15 bar owners or managers and the analyses of interviewers, the degrees of correlation between 17 SDGs and the drinking bar industry in China are divided into three groups (high-level, medium level, and low-level). Seven SDGs have a "high-level" correlation with the bar industry: SDG3, SDG4, SDG6, SDG8, SDG12, SDG14, and SDG15. Those with a "medium-level" correlation include SDG5, SDG7, SDG9, SDG11, and SDG17. The remaining five SDGs are SDG1, SDG2, SDG10, SDG13, and SDG16; they have a "low-level" correlation with bars, as shown in Figure 1. 
Table 2. Qualitative Interviews on SDGs with 15 Bars.

\begin{tabular}{|c|c|c|c|}
\hline SDGs & Bar Operators' Perception & Specific Actions of Bars & Future Suggestions \\
\hline $\begin{array}{l}\text { SDG1 } \\
\text { No Poverty }\end{array}$ & $\begin{array}{l}\text { 1. The topic is too big. Bar owners in first-tier } \\
\text { cities and catering and entertainment industries } \\
\text { think they can do little in this area. } \\
\text { 2. It mainly depends on relevant government } \\
\text { policies to improve it, such as regulating the } \\
\text { wage level and basic welfare. }\end{array}$ & $\begin{array}{l}\text { 1. The rise and prosperity of the bar industry have created more job opportunities for } \\
\text { society to some extent. }\end{array}$ & $\begin{array}{l}\text { 1. Make donations for the poor. } \\
\text { 2. Provide good welfare and protection for } \\
\text { employees. } \\
\text { 3. Ensure employees' legitimate income and rights } \\
\text { and interests. }\end{array}$ \\
\hline $\begin{array}{l}\text { SDG2 } \\
\text { Zero Hunger }\end{array}$ & 1. Save food. & $\begin{array}{l}\text { 1. Put an end to or reduce food wastage at restaurants: promote the concept of "empty } \\
\text { plate" on the tableware and tabletop at restaurants; } \\
\text { Specialized personnel are designated to supervise food wastage and take photos for } \\
\text { warning. }\end{array}$ & $\begin{array}{l}\text { 1. Let consumers understand the process "from } \\
\text { raw materials to dining tables" and arouse } \\
\text { awareness of conservation and environmental } \\
\text { protection. }\end{array}$ \\
\hline $\begin{array}{l}\text { SDG3 } \\
\text { Good Health and Well-being }\end{array}$ & $\begin{array}{l}\text { 1. The benefits of moderate drinking to mental } \\
\text { health. } \\
\text { 2. Protect consumers' diet health. } \\
\text { 3. Pay attention to employees' health and basic } \\
\text { welfare. }\end{array}$ & $\begin{array}{l}\text { 1. Advocate a healthy lifestyle and moderate drinking in bars in fast-paced cities: in } \\
\text { communication with guests and employees, advocate moderate drinking to relax the } \\
\text { body and mind after busy work. Cut down on the supply of high-concentration alcohol } \\
\text { products, and convert high-concentration alcohol into auxiliary materials for blending } \\
\text { through self-made methods such as soaking. } \\
\text { 2. Strictly control the quality and safety of food materials: supply food materials that } \\
\text { have passed safety certification. Regulate the length of food loss reporting. } \\
\text { 3. Remind and require employees to pay attention to work and rest arrangements and } \\
\text { avoid the inversion of day and night caused by the bar's business hours for good health. } \\
\text { 4. Provide basic accommodation for employees based on legal protection to ensure a } \\
\text { certain number of vacation days and free medical examinations. }\end{array}$ & $\begin{array}{l}\text { 1. Organize a comprehensive physical } \\
\text { examination in addition to that for the health } \\
\text { certificate yearly. } \\
\text { 2. Organize team sports and fitness activities. }\end{array}$ \\
\hline $\begin{array}{l}\text { SDG4 } \\
\text { Quality Education }\end{array}$ & $\begin{array}{l}\text { 1. Improve professional skills and knowledge } \\
\text { level. } \\
\text { 2. Pay attention to the long-term development } \\
\text { of employees. } \\
\text { 3. There is a close link with SDG } 8 \text { Decent Work } \\
\text { and Economic Growth. Only after people in the } \\
\text { industry receive high-quality education can they } \\
\text { have a better chance to have decent work, and } \\
\text { then decent work provides a foundation for } \\
\text { subsequent high-quality education, which } \\
\text { complement each other. }\end{array}$ & $\begin{array}{l}\text { 1. Improve professional skills and knowledge level through various forms of training: } \\
\text { ensure regular training of service knowledge, liquor knowledge, and blending skills } \\
\text { through team sharing or workshop sharing. Create a foreign language learning } \\
\text { atmosphere through English corners and incentive mechanisms for enhancing foreign } \\
\text { language proficiency. Encourage employees to persist in reading and learning and } \\
\text { share opinions with the team and guests. Provide staff with resources and financial } \\
\text { support for professional certification (such as WSET) and additional courses (such as } \\
\text { online management courses). } \\
\text { 2. Provide opportunities and support for employees' career development: in the form } \\
\text { of group or chain, provide opportunitief for employees' career development by } \\
\text { distributing stores and regions. In the form of communication, understand the } \\
\text { expectation of employees regarding their posts and the fields they wish to learn, and try } \\
\text { to satisfy them as much as possible through job rotation or functional adjustment. }\end{array}$ & $\begin{array}{l}\text { 1. Establish a bartender learning community to } \\
\text { share wine knowledge and formulas. } \\
\text { 2. Provide opportunities for overseas training and } \\
\text { exchange for employees. }\end{array}$ \\
\hline $\begin{array}{l}\text { SDG5 } \\
\text { Gender Equality }\end{array}$ & $\begin{array}{l}\text { 1. Respect and encourage female employees. } \\
\text { 2. Ensure gender equality. }\end{array}$ & $\begin{array}{l}\text { 1. The results of recruitment are not determined by gender. } \\
\text { 2. Understand and respect the advantages and disadvantages of each gender on the } \\
\text { objective conditions on the basis of equal treatment, and properly distribute the } \\
\text { functions: work results are not preset due to gender and female employees will not be } \\
\text { directly given special treatment due to the relative disadvantages of their physical } \\
\text { strength, but assistance will be given when they request support. Find the advantages } \\
\text { of women in work; for example, women will pay more attention to details. }\end{array}$ & $\begin{array}{l}\text { 1. At present, there is no problem with this matter } \\
\text { for most bar operators in the bar industry. On the } \\
\text { contrary, female employees are receiving more } \\
\text { and more preferential treatment, which may be } \\
\text { unfair for male employees. } \\
\text { 2. Therefore, while encouraging female } \\
\text { employees, it is also necessary to pay due } \\
\text { attention to the physical and mental development } \\
\text { of male employees and give them some care. }\end{array}$ \\
\hline
\end{tabular}


Table 2. Cont

SDGs

Bar Operators' Perception

Ensure water safety.

SDG6

2. Save water.

Clean Water and Sanitation $\quad$ 3. Sanitary bar environment.

SDG7

1. Save energy consumption

Affordable and Clean Energy $\quad$ 2. Use clean energy.

SDG8

Decent Work and Economic 1. Enhance the image of the service industry.

Growth

Specific Actions of Bars

1. Ensure the safety and sanitation of water used to clean food materials and drinking water. Use a professional water purification system to carry out regular inspection and maintenance of filtering devices. At the bar counter, separate the sinks for washing hands and for cleaning food materials.

anitation and tidiness of the bar environment: organize personnel to carry out the thorough cleaning of the bar regularly (e.g., weekly).

Regularly assign specialized personnel to inspect the health environment of each secto of the bar, and communicate the feedback of the results to each sector for reference an correction.

In the service proce
desktop in time.

1. Consider low energy consumption while purchasing electrical appliances: use mor materficient electrical appliances, such as air conditioners, refrigerators, and ice

ice makers in lights. For electrical appliances of high-energy consumption, such as use and cost of electric energy purchase one with a power-saving function to reduce the

2. Go easy on electrical appliances of high-energy consumption: In the blending formula, reduce the materials that need electric mixers and egg crackers, such as reducing the use of high-foaming egg white in blending and use a more efficient manual mixer bar after iterative improvement. Squeeze lemon juice manually.

3. Use clean energy: For bars with roofs or outdoor venues, the use of solar umbrellas, on the one hand, meets the needs of customers for outdoor electricity and, on the other hand, is also a more convenient option for bars (no external wiring board is required).

1. Cultivate self-confidence from inside to outside: enhance professional skills through training. Encourage employees to visit and observe other bars and learn from them. Encourage employees to enrich their knowledge and experience by reading and

traveling. Implement uniform clothing and etiquette standards.

2. Promote the recognition of the bar industry among the staff's relatives and friends: organize activities for the staff's families and let them visit the bar's internal working environment.

3. Guarantee a certain level of welfare benefits: provide basic accommodation, bonus, and vacation. Organize regular professional training. Provide opportunities and

support for employees' career development.

4. Help bar owners to provide relevant training on sustainable development for the staff.
Future Suggestions

1. Since this is the basic standard for business, every bar will follow it accordingly.

2. There is a considerable need for the

government's water treatment measures.

For example, all water used in Singapore

is recycled water, but drinking water

comes directly out of taps, which prove

that the government has done a lot

regarding recycled water.

1. Consider the whole running line in the design of the bar. By using the assembly line, water and energy can be saved in each step, such as turning on the tap once or twice.

1. Raise the bar's image in people's minds by raising the awareness level of the whole industry.

2. Through more platforms (such as variety shows), introduce the professional skills required for

bartending and the ability to grasp the knowledge of food materials, so that the public can have a more comprehensive understanding of the profession. 
Table 2. Cont.

SDGs

Bar Operators' Perception

1. Optimize and innovate bartending formulas
SDG9

Industry, Innovation, and

Infrastructure
1. Optimize
and tools.

2. Develop new products in the field of cocktail wine.

\author{
Specific Actions of Bars
}

Future Suggestions

1. Explore the possibilities of food materials by using new instruments such as centrifuges, distillers, acidification, and other chemical reactions. While obtaining innovative forms of bartending raw materials, make the best use of everything: transparent syrup is obtained by acidifying and decoloring milk, and cheese obtaine after acidification is used for other edible purposes. Pu er tea is decolored after distillation to ob in tra for other edible pup residue obtained after juicing tomatoes to obtain the decoration for bartending. 2. Try different bartending formulas and continuously develop cocktails according to and support the implementation of the market demand. Try to use chamomile and Chinese herbal medicine to make brewed wine and obtain more refreshing and unique taste. Develop more mojit formulas to meet the current demand for low alcohol and refreshing taste. 3. Develop new cocktail products: for example, establish an innovation laboratory to develop finished cocktails for use in bars and household bartending.

4. Use iterative bartending tools to improve efficiency and reduce energy consumption: improve the mixing head of manual mixing rod by using the principle of propelling turbine, from wood material to stainless steel material, making mixing more efficient and easy to clean and store. Use a measuring cup made with an improved manufacturing mold which has a longer service life because the upper part and the lower part are connected instead of being welded singly.

\section{SDG10}

Reduced Inequalities 1. China's bar industry has been developing China. To som extent, the gap between countries is narrowing.
1. Hire more foreign employees and bring more advanced foreign concepts and technologies into Chinese bars.

2. Invite well-known foreign bar operators to come to China as guest lecturers.
1. Some foreign employees say that the Chinese government has more restrictions on foreign employees, especially in the bar industry. For example, they must have a junior college degree or above. They hope that the policy of introducing forign policy of introducing foreign employees attract more advanced techniqus and expertise to Chinese bars.

1. Reduce the impact of noise and customer smoking on the surrounding residents through bar decoration and regional planning: use sound insulation glass extensively. Limit smoking areas to non-main streets or indoors. When organizing outdoor activities, control the end time of the activities, such as before 20:00. 2. Jointly safeguard the environment and interpersonal harmony of the community with the surrounding residents and dealers. Join organizations such as chambers of commerce and jointly organize comprehensive activities benefiting the community such as organizing free tasting activities at festivals and holding flea markets on a regular basis. Realize smooth communication and mutual assistance with community other business formats around the bars. Through simple garbage classification, plastic bottles, cardboard boxes, and other bartending knowledge with community recyclable waste products are given to those who collect garbage and waste products in residents. the community.

3. Benefit the community residents: provide the community residents with benefits, such as discounts at shops and preferential experience of new products. Sharing bartending knowledge and industry information with surrounding bars through guest or master courses. 
Table 2. Cont

SDGs
Bar Operators' Perception

1. Suppliers use more environment-friendly methods in the production, packaging, and

SDG12

Responsible Consumption

nd Production

2. Bar operators choose more

environment-friendly products.

3. Classify the garbage.

Specific Actions of Bars

1. Use degradable and recyclable bar articles: straw material, macaroni, bagasse, bamboo, wheat straw, and apple pomace pressed together. Cup mat material, cloth such as old denim, sawdust pressing, rattan, metal. Cup material, coconut shell (old coconut shell can ever be used as fuel), ceramic, metal, wood, PLA polylactic acid. 2. Reduce the use of coasters and straws. Some bars do not offer coasters and straws now. For example, using a cup with feet may not require a coaster.

3. Some wine morchants will 4. Large hotel groups such as Shangri-La will require every department to weigh the garbage every day to evaluate and improve the quantity and quality of food supplied.
SDG13

Climate Action

1. Use more energy-saving equipment

1. Use more energy-efficient equipment, such as refrigerators, air conditioners, ice makers, and LED lights.

Reduce waste of water resources: use professional, high-pressure cup washers to wash more efficiently. Recycle water resources, such as watering flowers with fish tank Advocate pure whiskey to reduce ice consumption.

2. Reduce the pollution of glass products: use empty wine bottles to decorate the bar, especially some high-grade wine bottles which can be used to decorate background walls. Use empty wine bottles to make candlesticks used in bars. Use empty wine bottles to contain homemade syrup, distilled liquor or raw materials.

3. Reduce the use of essence and spice: in the process of making cocktails, reduce or avoid chemical additives.

$\begin{array}{ll}\text { SDG } 14 & \text { 1. Save water } \\ \text { Life Below Water } & \text { 2. Reduce water pollution. }\end{array}$

4. Use a more environment-friendly cleaner or natural product as a cleaner: use natural grease in peels as a natural cleaner.

5. Use a more environment-friendly and energy-saving dishwasher and wait until the dishwasher is full of tableware before starting the cleaning.

6. Use a more advanced ice maker with a power-saving mode so that the produced ice cubes are not easy to melt, and the ice cubes do not need to be repeatedly made.

7. Regarding raw material production, reduce the use of chemicals, such as pesticides. 8 . The cork of the red wine bottle can be reused for things, such as decoration, floor mat,
Future Suggestions

1. Garbage classification is considered to be one of the ways to minimize pollution which is commonly agreed by many bar operators, but for now, there is a

consensus that mandatory measures by the government are needed. For examp after the mandatery requirent on garbage classification in Taiwan, people began to develop such habit gradually. 2. Foreign countries can choose the quality grade of their products. For example, strawberries with a less puctive appearance can also be purchased as raw materials instead of being discarded.

3. Consider the impact of raw materials on areas such as the environment and carbon emissions at the production site. 4. Garbage classification can be classifie according to recycling purposes and treatment methods.

1. Launch relevant initiatives and activities to raise awareness within the ange and learn from . Respond actively to the Paris Climate Agreement.

\section{Wine dealers should make plans for} recycling empty bottles.

2. With the "Ling Kao" method, wine dealers should use imported cans calculated in tons, and bars with which they have long-term cooperation can use old empty bottles.

3. It is expected that government departments will issue regulations on mandatory classification and recycling of glass and plastic products.

4. Consider the classification and

recycling of garbage, and classify the garbage according to different treatmen methods (such as natural degradation, incineration, and landfills). 
Table 2. Cont

\begin{tabular}{|c|c|c|c|}
\hline SDGs & Bar Operators' Perception & Specific Actions of Bars & Future Suggestions \\
\hline $\begin{array}{l}\text { SDG15 } \\
\text { Life on Land }\end{array}$ & $\begin{array}{l}\text { 1. Reduce the waste in the production process of } \\
\text { alcoholic products and make more rational use } \\
\text { of raw materials. }\end{array}$ & $\begin{array}{l}\text { 1. Make the best use of every fruit: the pulp can be juiced and the peel can be used for } \\
\text { cocktail decoration. The oil in the peel can be used to make natural dishwashing } \\
\text { essence (such as lemon essential oil soaked in lemon and alcohol, and foaming agent to } \\
\text { obtain natural dishwashing essence) or natural dishwashing essence, and the peel and } \\
\text { pomace can also be dried to make cookies. The squeezed fruit residue can be used for } \\
\text { making a fruit pie, porridge, fruit wine, or natural syrup after soaking. } \\
\text { 2. For a bar, the kitchen and the bar can share resources and make full use of raw } \\
\text { materials: the beef can be trimmed in the kitchen and used to extract flavor from the bar } \\
\text { to make Gin Tonic soup with the fresh flavor of beef. Basil leaves rosemary, which is not } \\
\text { fresh enough, cannot be used as a bartender material and can then be sent to the kitchen } \\
\text { to decorate the plate or used as spices for fried food. } \\
\text { 3. Self-grow and self-make raw materials for bartending: Use roof balcony or small } \\
\text { culture dish to plant rosemary and basil leaves, which are often used for bartending. } \\
\text { Milk is used as syrup, and the remaining residue is cheese, which can be used as a milk } \\
\text { cover. } \\
\text { 4. Categorization of kitchen waste: For example, salmon skins are distributed as food } \\
\text { for stray animals. }\end{array}$ & $\begin{array}{l}\text { 1. Encourage bars to use the remaining } \\
\text { peel to make natural detergent for } \\
\text { cleaning bowls, chopsticks, and cups, } \\
\text { which is low in cost and environmentally } \\
\text { friendly. } \\
\text { 2. Garbage shall be classified according } \\
\text { to recycling purposes and treatment } \\
\text { methods. }\end{array}$ \\
\hline $\begin{array}{l}\text { SDG16 } \\
\text { Peace, Justice, and Strong } \\
\text { Institutions }\end{array}$ & $\begin{array}{l}\text { 1. Maintain public order in the bar during } \\
\text { operation. }\end{array}$ & $\begin{array}{l}\text { 1. Prevent the occurrence of affrays and fights in bars. For example, remind friends } \\
\text { nearby appropriately on whether there is a need to take them home after drinking too } \\
\text { much, stop serving more drinks, and help find a driving service. }\end{array}$ & $\begin{array}{l}\text { 1. As a consensus among bar operators, } \\
\text { maintaining public order in bars is a } \\
\text { necessary norm, so there are no further } \\
\text { suggestions for the time being. }\end{array}$ \\
\hline $\begin{array}{l}\text { SDG17 } \\
\text { Partnerships for the Goals }\end{array}$ & $\begin{array}{l}\text { 1. In response to government or organization } \\
\text { calls, strictly implement the relevant regulations. }\end{array}$ & $\begin{array}{l}\text { 1. In some upscale communities in Shenzhen, Property Management will require all } \\
\text { catering dealers in the community to classify the garbage. } \\
\text { 2. In Beijing, bar owners in the Sanlitun area said that starting from April 1, 2019, all } \\
\text { catering dealers are required to make simple sorting and packaging of garbage. } \\
\text { 3. Share industry knowledge and basic formulas with fellow practitioners to create an } \\
\text { atmosphere of common exchange and learning. }\end{array}$ & $\begin{array}{l}\text { 1. Establish relevant industry } \\
\text { organizations and associations. } \\
\text { 2. Work with government and } \\
\text { non-governmental organizations. } \\
\text { 3. Communicate with, learn from and } \\
\text { work with international counterparts } \\
\text { and organizations. } \\
\text { 4. Actively respond to and participate in } \\
\text { the implementation of the } 2030 \text { Agenda } \\
\text { and SDGs. }\end{array}$ \\
\hline
\end{tabular}




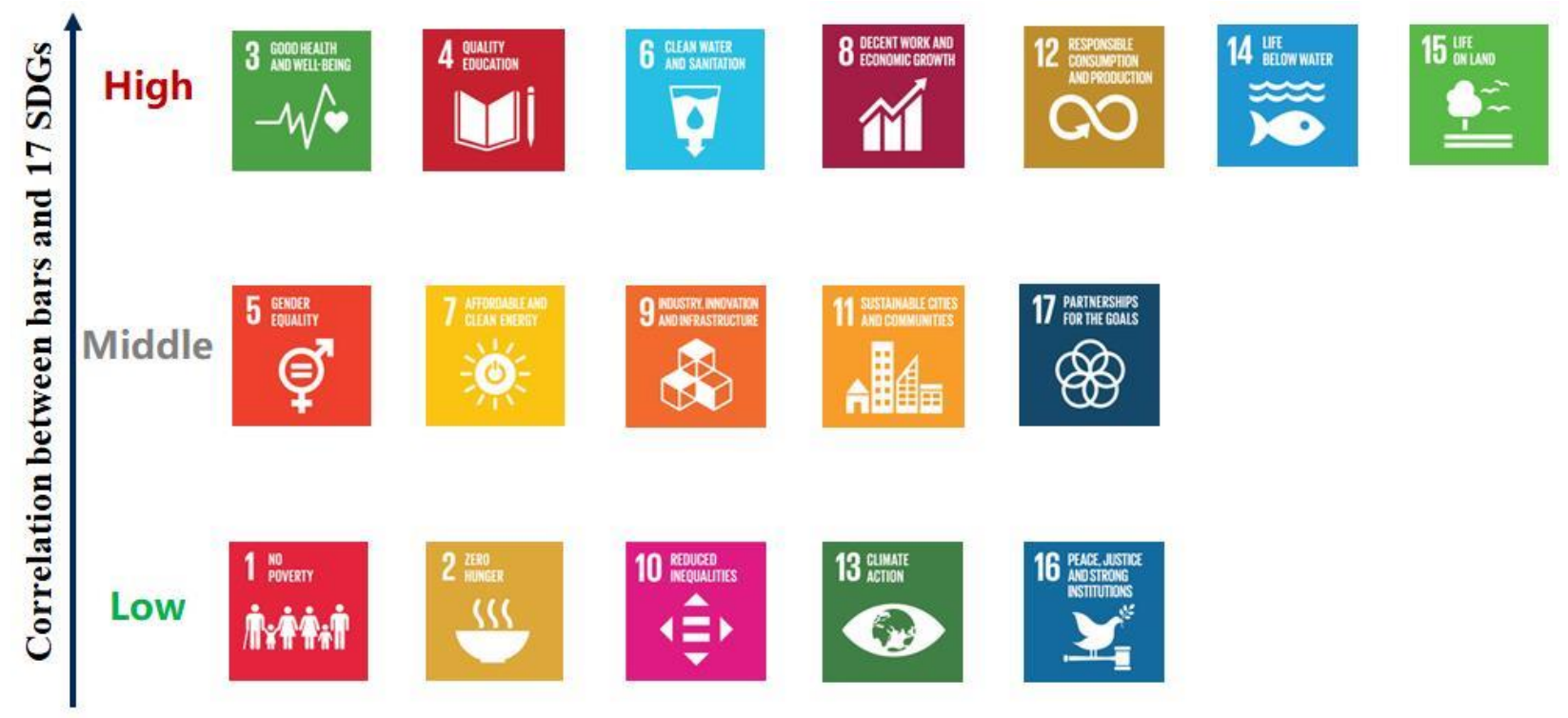

Figure 1. Qualitative Interview on the Correlation between China's Sustainable Bars and 17 SDGs.

\subsection{Quantitative Questionnaires and Results}

Based on the results and analysis of the preliminary desk research and qualitative interviews with 15 bars, a quantitative on-line questionnaire survey, which may take $10 \mathrm{~min}$ to complete with single choice or multiple choice, was conducted among a total of 321 bar practitioners (such as bar managers, bar waiters, bartender, bar operators, and bar sales) in Shanghai, Shenzhen, and Beijing. Based on the 32 items about bar operators' perception, 49 items about specific actions of bars, and 35 items about future ideas and suggestions from the qualitative interviews, the questionnaires concluded basic information (such as working experience, working years, age, gender, type of work, bar type etc.), basic questions about sustainable development and questions about 105 specific items of bars' actions towards 17 SDGs as shown in Tables 3-5. Before completing questions of on-line questionnaire about sustainable development, the conception of sustainable development is introduced on-line in Chinese as "Sustainable development is the consensus reached by all mankind. It is a way for development that not only meets the needs of current generation, but also does not harm the needs of future generations. Human society not only achieves the goal of economic development, but also protects the natural resources and environment such as the atmosphere, freshwater, oceans, land and forests that are important for the living and development of future generations. It is also included in national development strategies. In order to achieve sustainable development, all people in our society no matter what kind of job he has should work together". Before completing the on-line questionnaire about the 2030 Agenda and 17 SDGs, its conception is introduced on-line in Chinese as: "In 2015, on the basis of the implementation of the Millennium Development Goals (MDGs), the United Nations adopted the document of Transforming our World: The 2030 Agenda for Sustainable Development and 17 Sustainable Development Goals, integrating economic, social and environmental aspects, five dimensions of people, planet, prosperity, peace and partnership, and 169 targets and 232 indicators."

For each item in questionnaire, bar practitioners should have single choice or multiple choices. Different items in questionnaire may have logic links and only effective answers are collected so the total valid number for each item may not be 321 , which is the total number of bar practitioners. The results of basic information in Table 3 show that most of bar practitioners have 1-2 years of experience in alcohol industry and current bars. Further, $56.1 \%$ of them have an age range of $18-24$ and $26.2 \%$ of them have an age range of 25-29. Most of them about $69.0 \%$ are male and $31.0 \%$ are female. Most of bar practitioners have working duty as bartender and then bar waiter. 82 bars in 301 belong to whisky bar. The quantitative results in Table 4 for sustainable development show that the proportion of topics that bar practitioners mainly focus on is (from large to small) as follows: economic development, sports 
entertainment, food safety, sustainable development, environmental protection, international relations, history and humanities, current affairs, and politics. Nearly $57.8 \%$ of practitioners think sustainable development is very important for bar industry in China. Moreover, $49.8 \%$ of the practitioners often discuss about sustainable development in bar industry, especially in Shenzhen. 61.3\% of them have very positive attitude towards sustainable development in bar industry. However, $61.5 \%$ of them seldom hear or witness actions for sustainable development of colleagues. Overall, everyone takes a positive attitude towards environmental protection and sustainable development, but the specific cognition is still limited.

Table 3. Basic information and data of quantitative questionnaire.

\begin{tabular}{|c|c|c|c|c|c|c|c|}
\hline \multicolumn{8}{|c|}{ Basic Information and Data. } \\
\hline & \multicolumn{4}{|c|}{ In Number (N) } & \multicolumn{3}{|c|}{ In Percentage (\%) of Valid Total } \\
\hline & Total (\%) & Shanghai & Shenzhen & Beijing & Shanghai & Shenzhen & Beijing \\
\hline Base & 321 & 114 & 105 & 102 & $35.5 \%$ & $32.7 \%$ & $31.8 \%$ \\
\hline \multicolumn{8}{|c|}{ Years of experience in alcohol industry (single choice) } \\
\hline 1 year and below & $99(32.6 \%)$ & 36 & 30 & 33 & $11.8 \%$ & $9.9 \%$ & $10.9 \%$ \\
\hline 2 years & $77(25.3 \%)$ & 24 & 29 & 24 & $7.9 \%$ & $9.5 \%$ & $7.9 \%$ \\
\hline 3 years & $46(15.1 \%)$ & 13 & 15 & 18 & $4.3 \%$ & $4.9 \%$ & $5.9 \%$ \\
\hline 4 years & $23(7.6 \%)$ & 4 & 9 & 10 & $1.3 \%$ & $3.0 \%$ & $3.3 \%$ \\
\hline 5 years & $13(4.3 \%)$ & 7 & 1 & 5 & $2.3 \%$ & $0.3 \%$ & $1.6 \%$ \\
\hline 6 years & $9(3.0 \%)$ & 5 & 2 & 2 & $1.6 \%$ & $0.7 \%$ & $0.7 \%$ \\
\hline 7 years & $6(2.0 \%)$ & 2 & 2 & 2 & $0.7 \%$ & $0.7 \%$ & $0.7 \%$ \\
\hline 8 years & $8(2.6 \%)$ & 2 & 4 & 2 & $0.7 \%$ & $1.3 \%$ & $0.7 \%$ \\
\hline 9 years & $4(1.3 \%)$ & 2 & 1 & 1 & $0.7 \%$ & $0.3 \%$ & $0.3 \%$ \\
\hline 10 years and above & $19(6.3 \%)$ & 6 & 9 & 4 & $2.0 \%$ & $3.0 \%$ & $1.3 \%$ \\
\hline Valid Total & 304 & 101 & 102 & 101 & $33.2 \%$ & $33.6 \%$ & $33.2 \%$ \\
\hline \multicolumn{8}{|c|}{ Years of service at the current bar (single choice) } \\
\hline 1 year and below & $129(42.9 \%)$ & 37 & 50 & 42 & $12.3 \%$ & $16.6 \%$ & $14.0 \%$ \\
\hline 2 years & $98(32.2 \%)$ & 36 & 35 & 27 & $12.0 \%$ & $11.6 \%$ & $9.0 \%$ \\
\hline 3 years & $39(13.0 \%)$ & 12 & 7 & 20 & $4.0 \%$ & $2.3 \%$ & $6.6 \%$ \\
\hline 4 years & $12(4.0 \%)$ & 4 & 2 & 6 & $1.3 \%$ & $0.7 \%$ & $2.0 \%$ \\
\hline 5 years and above & $23(7.6 \%)$ & 11 & 7 & 5 & $3.7 \%$ & $2.3 \%$ & $1.7 \%$ \\
\hline Valid Total & 301 & 100 & 101 & 100 & $33.2 \%$ & $33.6 \%$ & $33.2 \%$ \\
\hline \multicolumn{8}{|c|}{ Age (single choice) } \\
\hline $18-24$ & $169(56.1 \%)$ & 64 & 49 & 56 & $21.3 \%$ & $16.3 \%$ & $18.6 \%$ \\
\hline $25-29$ & $79(26.2 \%)$ & 21 & 27 & 31 & $7.0 \%$ & $9.0 \%$ & $10.3 \%$ \\
\hline $30-34$ & $27(9.0 \%)$ & 8 & 10 & 9 & $2.7 \%$ & $3.3 \%$ & $3.0 \%$ \\
\hline $35-39$ & $20(6.6 \%)$ & 4 & 14 & 2 & $1.3 \%$ & $4.7 \%$ & $0.7 \%$ \\
\hline $40-44$ & $1(0.3 \%)$ & 1 & 0 & 0 & $0.3 \%$ & $0.0 \%$ & $0.0 \%$ \\
\hline $45-49$ & $3(1.0 \%)$ & 2 & 0 & 1 & $0.7 \%$ & $0.0 \%$ & $0.3 \%$ \\
\hline $50-54$ & 0 & 0 & 0 & 0 & $0.0 \%$ & $0.0 \%$ & $0.0 \%$ \\
\hline $55-59$ & $2(0.7 \%)$ & 1 & 0 & 1 & $0.3 \%$ & $0.0 \%$ & $0.3 \%$ \\
\hline Valid Total & 301 & 101 & 100 & 100 & $33.6 \%$ & $33.2 \%$ & $33.2 \%$ \\
\hline \multicolumn{8}{|c|}{ Gender (single choice) } \\
\hline male & $207(69.0 \%)$ & 68 & 71 & 68 & $22.7 \%$ & $23.7 \%$ & $22.7 \%$ \\
\hline female & $93(31.0 \%)$ & 32 & 29 & 32 & $10.7 \%$ & $9.7 \%$ & $10.7 \%$ \\
\hline Valid Total & 300 & 100 & 100 & 100 & $33.3 \%$ & $33.3 \%$ & $33.3 \%$ \\
\hline
\end{tabular}


Table 3. Cont.

\begin{tabular}{cccccccc}
\hline \multicolumn{7}{c}{ Basic Information and Data. } \\
\hline \multicolumn{7}{c}{ In Number (N) } & \multicolumn{2}{c}{ In Percentage (\%) of Valid Total } \\
\hline & Total (\%) & Shanghai & Shenzhen & Beijing & Shanghai & Shenzhen & Beijing \\
\hline bar manager & 72 & 23 & 26 & 23 & $6.1 \%$ & $7.0 \%$ & $6.1 \%$ \\
\hline bar waiter & 98 & 31 & 33 & 34 & $8.3 \%$ & $8.8 \%$ & $9.1 \%$ \\
\hline bartender & 107 & 40 & 33 & 34 & $10.7 \%$ & $8.8 \%$ & $9.1 \%$ \\
\hline bar operator & 58 & 20 & 24 & 14 & $5.3 \%$ & $6.4 \%$ & $3.7 \%$ \\
\hline bar sales & 39 & 9 & 16 & 14 & $2.4 \%$ & $4.3 \%$ & $3.7 \%$ \\
\hline Valid Total & 374 & 123 & 132 & 119 & $32.9 \%$ & $35.3 \%$ & $31.8 \%$ \\
\hline Whisky bar & $82(27.2 \%)$ & 25 & 34 & 23 & $8.3 \%$ & $11.3 \%$ & $7.6 \%$ \\
\hline Restaurant bar & $64(21.3 \%)$ & 25 & 14 & 25 & $8.3 \%$ & $4.7 \%$ & $8.3 \%$ \\
\hline Cocktail/speakeasy bar & $64(21.3 \%)$ & 13 & 28 & 23 & $4.3 \%$ & $9.3 \%$ & $7.6 \%$ \\
\hline High energy bars & $25(8.3 \%)$ & 11 & 5 & 9 & $3.7 \%$ & $1.7 \%$ & $3.0 \%$ \\
\hline Live house & $39(13.0 \%)$ & 16 & 9 & 14 & $5.3 \%$ & $3.0 \%$ & $4.7 \%$ \\
\hline Lounge/hotel lounge & $6(2.0 \%)$ & 4 & 1 & 1 & $1.3 \%$ & $0.3 \%$ & $0.3 \%$ \\
\hline Wine bar & $8(2.7 \%)$ & 1 & 4 & 3 & $0.3 \%$ & $1.3 \%$ & $1.0 \%$ \\
\hline Pub/dive bar & $10(3.3 \%)$ & 4 & 3 & 3 & $1.3 \%$ & $1.0 \%$ & $1.0 \%$ \\
\hline Others & $3(1.0 \%)$ & 0 & 3 & 0 & $0.0 \%$ & $1.0 \%$ & $0.0 \%$ \\
\hline Valid Total & 301 & 99 & 101 & 101 & $32.9 \%$ & $33.6 \%$ & $33.6 \%$ \\
\hline
\end{tabular}

Table 4. Question towards sustainable development and data in questionnaire.

\begin{tabular}{cccccccc}
\hline \multicolumn{7}{c}{ Topics of Sustainable Development and Data } \\
\hline \multicolumn{7}{c}{ In Number (N) } & \multicolumn{3}{c}{ In Percentage (\%) of Valid Total } \\
\hline & Total (\%) & Shanghai & Shenzhen & Beijing & Shanghai & Shenzhen & Beijing \\
\hline \multicolumn{7}{c}{ Concerned topics in life and work (multiple choices) } \\
\hline Economic development & 168 & 59 & 58 & 51 & $7.8 \%$ & $7.7 \%$ & $6.7 \%$ \\
\hline Sports entertainment & 120 & 34 & 40 & 46 & $4.5 \%$ & $5.3 \%$ & $6.1 \%$ \\
\hline Food safety & 108 & 30 & 47 & 31 & $4.0 \%$ & $6.2 \%$ & $4.1 \%$ \\
\hline $\begin{array}{c}\text { Sustainable } \\
\text { development }\end{array}$ & 88 & 22 & 37 & 29 & $2.9 \%$ & $4.9 \%$ & $3.8 \%$ \\
\hline $\begin{array}{c}\text { Environmental } \\
\text { protection }\end{array}$ & 75 & 18 & 35 & 22 & $2.4 \%$ & $4.6 \%$ & $2.9 \%$ \\
\hline International relations & 73 & 19 & 28 & 26 & $2.5 \%$ & $3.7 \%$ & $3.4 \%$ \\
\hline History and humanities & 67 & 20 & 30 & 17 & $2.6 \%$ & $4.0 \%$ & $2.2 \%$ \\
\hline Political issues & 58 & 19 & 22 & 17 & $2.5 \%$ & $2.9 \%$ & $2.2 \%$ \\
\hline Thery important & $174(57.8 \%)$ & 59 & 60 & 55 & $19.6 \%$ & $19.9 \%$ & $18.3 \%$ \\
\hline Important & $94(31.2 \%)$ & 32 & 30 & 32 & $10.6 \%$ & $10.0 \%$ & $10.6 \%$ \\
\hline Normal & $18(6.0 \%)$ & 5 & 7 & 6 & $1.7 \%$ & $2.3 \%$ & $2.0 \%$ \\
\hline Not so important & $9(3.0 \%)$ & 3 & 2 & 4 & $1.0 \%$ & $0.7 \%$ & $1.3 \%$ \\
\hline Unimportant & $6(2.0 \%)$ & 1 & 2 & 3 & $0.3 \%$ & $0.7 \%$ & $1.0 \%$ \\
\hline Valid Total & 301 & 100 & 101 & 100 & $33.2 \%$ & $33.6 \%$ & $33.2 \%$ \\
\hline
\end{tabular}


Table 4. Cont.

\begin{tabular}{|c|c|c|c|c|c|c|c|}
\hline \multicolumn{8}{|c|}{ Topics of Sustainable Development and Data } \\
\hline & \multicolumn{4}{|c|}{ In Number (N) } & \multicolumn{3}{|c|}{ In Percentage (\%) of Valid Total } \\
\hline & Total (\%) & Shanghai & Shenzhen & Beijing & Shanghai & Shenzhen & Beijing \\
\hline \multicolumn{8}{|c|}{ Have you ever discussed about sustainable development in bar industry? (single choice) } \\
\hline Often & $149(49.8 \%)$ & 47 & 60 & 42 & $15.7 \%$ & $20.1 \%$ & $14.0 \%$ \\
\hline Seldom & $128(42.8 \%)$ & 47 & 32 & 49 & $15.7 \%$ & $10.7 \%$ & $16.4 \%$ \\
\hline Never & $22(7.4 \%)$ & 5 & 8 & 9 & $1.7 \%$ & $2.7 \%$ & $3.0 \%$ \\
\hline Valid Total & 299 & 99 & 100 & 100 & $33.1 \%$ & $33.4 \%$ & $33.4 \%$ \\
\hline \multicolumn{8}{|c|}{ Have you heard or witnessed that colleagues have taken actions related to sustainable development? (single choice) } \\
\hline Often & $94(31.2 \%)$ & 37 & 25 & 32 & $12.3 \%$ & $8.3 \%$ & $10.6 \%$ \\
\hline Seldom & $185(61.5 \%)$ & 58 & 67 & 60 & $19.3 \%$ & $22.3 \%$ & $19.9 \%$ \\
\hline Never & $22(7.3 \%)$ & 5 & 9 & 8 & $1.7 \%$ & $3.0 \%$ & $2.7 \%$ \\
\hline Valid Total & 301 & 100 & 101 & 100 & $33.2 \%$ & $33.6 \%$ & $33.2 \%$ \\
\hline \multicolumn{8}{|c|}{ Attitudes towards sustainable development in bar industry (single choice) } \\
\hline Agree & $184(61.3 \%)$ & 54 & 73 & 57 & $18.0 \%$ & $24.3 \%$ & $19.0 \%$ \\
\hline Watch & $85(28.3 \%)$ & 33 & 19 & 33 & $11.0 \%$ & $6.3 \%$ & $11.0 \%$ \\
\hline Doubt & $23(7.7 \%)$ & 11 & 5 & 7 & $3.7 \%$ & $1.7 \%$ & $2.3 \%$ \\
\hline Disagree & $8(2.7 \%)$ & 2 & 3 & 3 & $0.7 \%$ & $1.0 \%$ & $1.0 \%$ \\
\hline Valid Total & 300 & 100 & 100 & 100 & $33.3 \%$ & $33.3 \%$ & $33.3 \%$ \\
\hline
\end{tabular}

Thus, to test bar practitioners' attitudes and actions on the 17 SDGs and their 105 specific items of actions, first the questionnaires adopt a five-item scoring system (1-5: 1 means completely irrelevant, 5 means very relevant) for 17 SDGs and calculate their average scores which presents its relevance with bar industry as in Figure 2. Regarding bar practitioners' actions towards 105 items, the results of whether the 105 items have been taken into actions in their bars in percentage and their rankings are listed in Table 4. By the degree of correlation among the 17 SDGs, seven have a "high-level" correlation with the bar industry in the quantitative research: SDG8, SDG6, SDG7, SDG17, SDG12, SDG11, and SDG5. Those with a "medium-level" correlation include SDG9, SDG10, SDG16, SDG15, SDG3, and SDG4, while those with a "low-level" correlation include SDG13, SDG14, SDG2, and SDG1.

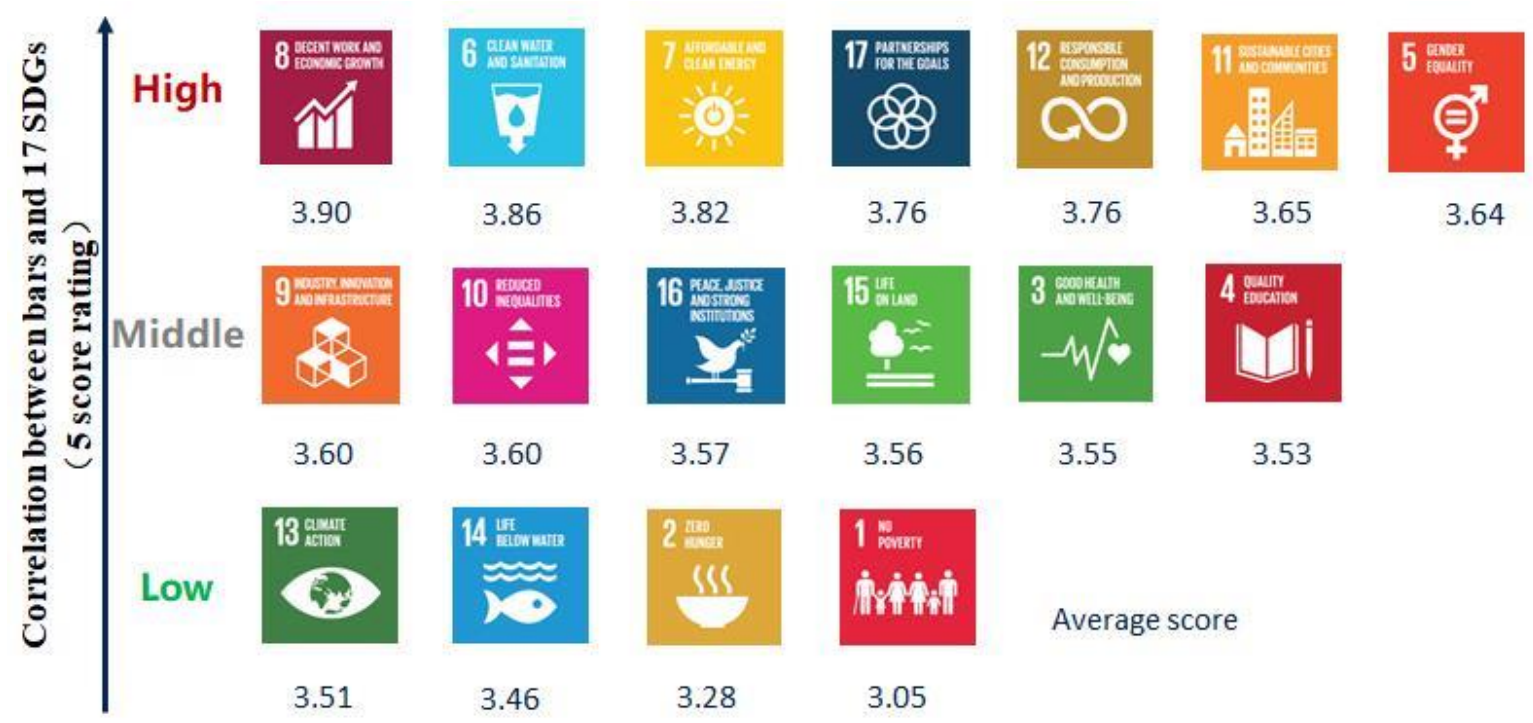

Figure 2. Quantitative questionnaire on the Correlation between China's Sustainable Bars and 17 SDGs. 
Table 5. Quantitative questionnaire about actions of bars.

\begin{tabular}{|c|c|c|}
\hline 105 Specific Items of Bars' Actions & 17 SDGs & Actions Taken \\
\hline Ensure employees' legitimate income, rights, and interests & SDG1 & $76 \%$ \\
\hline $\begin{array}{l}\text { Advise customers not to drive after drinking and provide substitute driving } \\
\text { services }\end{array}$ & SDG16 & $74 \%$ \\
\hline Provide good welfare and protection for employees & SDG1 & $74 \%$ \\
\hline Jointly safeguard the social order in the bar and its surrounding areas & SDG16 & $72 \%$ \\
\hline $\begin{array}{l}\text { Let consumers understand the process "from raw materials to dining tables" } \\
\text { and arouse the awareness of conservation and environmental protection }\end{array}$ & SDG2 & $71 \%$ \\
\hline $\begin{array}{l}\text { Make regular (e.g., weekly) organization and arrangement of staff for thorough } \\
\text { cleaning of the bar }\end{array}$ & SDG6 & $67 \%$ \\
\hline $\begin{array}{l}\text { Use a professional water purification system to carry out regular inspection } \\
\text { and maintenance of the filtering device }\end{array}$ & SDG6 & $66 \%$ \\
\hline $\begin{array}{l}\text { In the process of service, clean up the used paper towel and other garbage on } \\
\text { the guest's desktop in time }\end{array}$ & SDG6 & $65 \%$ \\
\hline Prevent the occurrence of affrays and fights in bars & SDG16 & $65 \%$ \\
\hline Upgrade professional skills through training & SDG4 & $63 \%$ \\
\hline Advocate moderate drinking in communication with guests and employees & SDG3 & $63 \%$ \\
\hline Develop new products in the cocktail field & SDG9 & $60 \%$ \\
\hline $\begin{array}{l}\text { Use more energy-efficient devices such as refrigerators, air conditioners, ice } \\
\text { makers, and LED lights. }\end{array}$ & SDG7 & $60 \%$ \\
\hline Supply food materials that have passed safety certification & SDG3 & $59 \%$ \\
\hline Strengthen team sharing and learn from each other & SDG4 & $59 \%$ \\
\hline Encourage employees to persist in reading and studying & SDG4 & $59 \%$ \\
\hline Encourage employees to visit and observe other bars to learn from them & SDG4 & $58 \%$ \\
\hline Use degradable and recyclable bar articles & SDG12 & $58 \%$ \\
\hline $\begin{array}{l}\text { Encourage employees to enrich their knowledge and experience through } \\
\text { reading and traveling }\end{array}$ & SDG4 & $57 \%$ \\
\hline Separate the sink for washing hands and that for cleaning food materials & SDG6 & $57 \%$ \\
\hline $\begin{array}{l}\text { Provide Chinese employees with opportunities for training and exchange at } \\
\text { home and abroad }\end{array}$ & SDG4 & $57 \%$ \\
\hline $\begin{array}{l}\text { Implant the concept of "empty plate" into the tableware and tabletop of the } \\
\text { staff restaurant }\end{array}$ & SDG2 & $57 \%$ \\
\hline $\begin{array}{l}\text { Some foreign employees say that they hope that the policy of introducing } \\
\text { foreign employees to bars can be relaxed in the future to attract more advanced } \\
\text { techniques and expertise to Chinese bars }\end{array}$ & SDG10 & $56 \%$ \\
\hline Implement uniform clothing and etiquette standards & SDG8 & $54 \%$ \\
\hline Use LED lights for climate change & SDG13 & $54 \%$ \\
\hline Reduce the use of coasters and straws & SDG12 & $54 \%$ \\
\hline Determine the position by ability and experience & SDG5 & $54 \%$ \\
\hline $\begin{array}{l}\text { Optimize and innovate the blending formulas to make the best use of raw } \\
\text { materials }\end{array}$ & SDG15 & $54 \%$ \\
\hline Reduce waste of water resources & SDG14 & $54 \%$ \\
\hline $\begin{array}{l}\text { Communicate with, learn from, and work with international peers and } \\
\text { organizations (such as guest bartenders) }\end{array}$ & SDG17 & $53 \%$ \\
\hline Invite well-known foreign bar operators to visit China as guest lecturers & SDG10 & $53 \%$ \\
\hline $\begin{array}{l}\text { Establish a bartender learning community to share wine knowledge and } \\
\text { formula }\end{array}$ & SDG4 & $53 \%$ \\
\hline $\begin{array}{l}\text { Exchange and learn from international peers. Respond actively to the Paris } \\
\text { Climate Agreement }\end{array}$ & SDG13 & $53 \%$ \\
\hline Recruitment results and salary standards are not determined by gender & SDG5 & $52 \%$ \\
\hline
\end{tabular}


Table 5. Cont.

\begin{tabular}{|c|c|c|}
\hline 105 Specific Items of Bars' Actions & 17 SDGs & Actions Taken \\
\hline Make full use of raw materials & SDG15 & $52 \%$ \\
\hline Classify the garbage according to recycling purposes and treatment methods & SDG12 & $52 \%$ \\
\hline $\begin{array}{l}\text { Use more energy-efficient electrical appliances such as air conditioners, } \\
\text { refrigerators, ice makers, etc. }\end{array}$ & SDG7 & $51 \%$ \\
\hline Squeeze lemon juice manually & SDG7 & $51 \%$ \\
\hline Reuse the wooden cases for loading & SDG12 & $51 \%$ \\
\hline Care about the physical and mental life of female employees & SDG5 & $51 \%$ \\
\hline Care about the physical and mental life of male employees as well & SDG5 & $51 \%$ \\
\hline Self-grow/self-make raw materials for bartending & SDG15 & $51 \%$ \\
\hline Hold regular lectures on wine culture for neighborhood & SDG11 & $50 \%$ \\
\hline $\begin{array}{l}\text { Assign specialized personnel to inspect the health environment of various } \\
\text { sectors of the bar }\end{array}$ & SDG6 & $49 \%$ \\
\hline Establish bar organizations and associations & SDG17 & $49 \%$ \\
\hline Advocate the use of natural pollution-free detergent & SDG15 & $49 \%$ \\
\hline Use a cleaner that is more environmentally friendly or natural as the cleaner & SDG14 & $49 \%$ \\
\hline $\begin{array}{l}\text { In terms of raw material production, reduce the use of chemicals such as } \\
\text { pesticides }\end{array}$ & SDG14 & $49 \%$ \\
\hline $\begin{array}{l}\text { The area requires all catering dealers to do simple sorting and packaging of } \\
\text { garbage }\end{array}$ & SDG17 & $48 \%$ \\
\hline $\begin{array}{l}\text { Use iterative bartending tools to improve efficiency and reduce energy } \\
\text { consumption }\end{array}$ & SDG9 & $48 \%$ \\
\hline $\begin{array}{l}\text { Launch relevant initiatives and activities to improve the industry's internal } \\
\text { awareness of climate change }\end{array}$ & SDG13 & $48 \%$ \\
\hline Reduce the use of chemically synthesized flavors and fragrances & SDG14 & $48 \%$ \\
\hline Provide basic accommodation, bonus, vacation & SDG8 & $47 \%$ \\
\hline Limit smoking areas to non-main streets or indoors & SDG11 & $47 \%$ \\
\hline Remind and require employees to pay attention to work and rest arrangements & SDG3 & $47 \%$ \\
\hline $\begin{array}{l}\text { Create a language learning atmosphere for service staff through English } \\
\text { corners/Chinese corners }\end{array}$ & SDG4 & $47 \%$ \\
\hline $\begin{array}{l}\text { Provide staff with resources and financial support for professional certification } \\
\text { (e.g., WSET) and additional courses (e.g., online management courses) }\end{array}$ & SDG4 & $47 \%$ \\
\hline $\begin{array}{l}\text { Designate specialized personnel to supervise food waste and take photos for } \\
\text { warning }\end{array}$ & SDG2 & $47 \%$ \\
\hline Make the best use of every fruit & SDG15 & $46 \%$ \\
\hline Regulate the time length of food use and storage & SDG3 & $46 \%$ \\
\hline Provide employees with the opportunity to rotate positions or adjust duties & SDG4 & $46 \%$ \\
\hline Organize professional training regularly & SDG8 & $45 \%$ \\
\hline $\begin{array}{l}\text { Set up an innovative laboratory to develop finished cocktails for bar and } \\
\text { household bartending purposes }\end{array}$ & SDG9 & $45 \%$ \\
\hline $\begin{array}{l}\text { Encourage the innovation of bartending technology and support technical } \\
\text { practice }\end{array}$ & SDG9 & $45 \%$ \\
\hline Reduce the use of electric mixers and eggbeaters & SDG7 & $44 \%$ \\
\hline $\begin{array}{l}\text { The property requires all catering dealers in the community to do garbage } \\
\text { sorting }\end{array}$ & SDG17 & $44 \%$ \\
\hline Select the quality grade of product supply to avoid waste & SDG12 & $44 \%$ \\
\hline $\begin{array}{l}\text { Garbage can be classified according to recycling purposes and treatment } \\
\text { methods }\end{array}$ & SDG12 & $44 \%$ \\
\hline Wine dealers should make plans for recycling empty bottles & SDG15 & $44 \%$ \\
\hline
\end{tabular}


Table 5. Cont.

\begin{tabular}{|c|c|c|}
\hline 105 Specific Items of Bars' Actions & 17 SDGs & Actions Taken \\
\hline Use the sound insulation glass extensively & SDG11 & $43 \%$ \\
\hline Buy ice machines with power-saving function & SDG7 & $42 \%$ \\
\hline Use clean energy (such as solar energy and wind energy) & SDG7 & $42 \%$ \\
\hline Work with government and non-governmental organizations & SDG17 & $42 \%$ \\
\hline $\begin{array}{l}\text { Consider the impact of raw materials on areas such as the environment and } \\
\text { carbon emissions at the production site }\end{array}$ & SDG12 & $42 \%$ \\
\hline $\begin{array}{l}\text { When organizing outdoor activities, control the end time of the activities, such } \\
\text { as before } 8 \text { p.m. }\end{array}$ & SDG11 & $42 \%$ \\
\hline Use new instruments or tools for bartending & SDG9 & $42 \%$ \\
\hline Reduce pollution of glass products & SDG14 & $42 \%$ \\
\hline $\begin{array}{l}\text { Optimize operation and management processes to save energy and adopt clean } \\
\text { energy }\end{array}$ & SDG7 & $41 \%$ \\
\hline Reduce the supply of high-concentration alcohol products & SDG3 & $41 \%$ \\
\hline $\begin{array}{l}\text { Provide basic accommodation for employees to ensure a certain number of } \\
\text { vacation days and free medical examinations }\end{array}$ & SDG3 & $41 \%$ \\
\hline Help clean streets and neighborhoods & SDG11 & $40 \%$ \\
\hline Only when the dishwasher is full of tableware can it be started for washing & SDG14 & $40 \%$ \\
\hline $\begin{array}{l}\text { Actively respond to and participate in the implementation of the } 2030 \text { Agenda } \\
\text { and SDGs }\end{array}$ & SDG17 & $39 \%$ \\
\hline $\begin{array}{l}\text { Organize activities for the staff's families and let them visit the bar's internal } \\
\text { working environment }\end{array}$ & SDG8 & $38 \%$ \\
\hline Provide opportunities and support for employees' career development & SDG8 & $38 \%$ \\
\hline $\begin{array}{l}\text { Improve the image of bars in people's minds by raising the awareness level of } \\
\text { the whole industry }\end{array}$ & SDG8 & $38 \%$ \\
\hline Weigh the garbage to assess whether there is wastage & SDG12 & $38 \%$ \\
\hline Advocate water conservation and joint compliance in the industry & SDG6 & $37 \%$ \\
\hline $\begin{array}{l}\text { Provide community residents with discounts at shops, the preferential } \\
\text { experience of new products, and other benefits }\end{array}$ & SDG11 & $37 \%$ \\
\hline The government should issue relevant recycling policies and standards & SDG14 & $37 \%$ \\
\hline Hold community public welfare activities regularly & SDG11 & $36 \%$ \\
\hline Organize team sports and fitness activities & SDG3 & $36 \%$ \\
\hline Raise money for the poor & SDG1 & $36 \%$ \\
\hline Respond to the call of the government and save water & SDG6 & $35 \%$ \\
\hline Wine dealers should make plans for recycling empty bottles & SDG14 & $35 \%$ \\
\hline Recover old empty bottles and tanks & SDG14 & $35 \%$ \\
\hline Use a more advanced ice maker with a power-saving mode & SDG14 & $34 \%$ \\
\hline $\begin{array}{l}\text { Hire more foreign employees and bring more advanced ideas and technologies } \\
\text { from abroad into Chinese bars }\end{array}$ & SDG10 & $33 \%$ \\
\hline $\begin{array}{l}\text { Provide employees with opportunities for training and communication at } \\
\text { home and abroad }\end{array}$ & SDG4 & $33 \%$ \\
\hline Garbage is classified according to recycling purposes and treatment methods & SDG15 & $30 \%$ \\
\hline Work with relevant institutions and manufacturers in terms of innovation & SDG9 & $28 \%$ \\
\hline Make secondary utilization of red wine bottle corks & SDG14 & $28 \%$ \\
\hline Create community shared space and interact with the community & SDG11 & $27 \%$ \\
\hline Suggest government to issue relevant recycling policies and standards & SDG14 & $27 \%$ \\
\hline $\begin{array}{l}\text { Let the public gain a more comprehensive understanding of the profession } \\
\text { through more platforms (such as variety shows) }\end{array}$ & SDG8 & $25 \%$ \\
\hline
\end{tabular}




\subsection{Comprehensive Results Based on Qualitative Interviews and Quantitative Questionnaires}

Combining the qualitative and quantitative results, the coordinate axis distribution arrangement (the vertical axis is the result of qualitative interviews, and the horizontal axis is the result of the quantitative questionnaires) is made for the correlation between the 17 SDGs and the drinking bar industry in China (Super High, High, Middle, Low, and Super Low) as showed in Figure 3. The correlation of SDG8, SDG6, and SDG12, respectively, with Chinese bars, is super high. That of SDG13, SDG2, and SDG1 is super low. Overall, Chinese bar practitioners take a positive attitude towards environmental protection and sustainable development, but the actual operation or specific cognition is still limited. It is of great significance to promote the sustainable development of Chinese bars in combination with the international and domestic sustainable development background, especially the 2030 Agenda and the 17 SDGs.

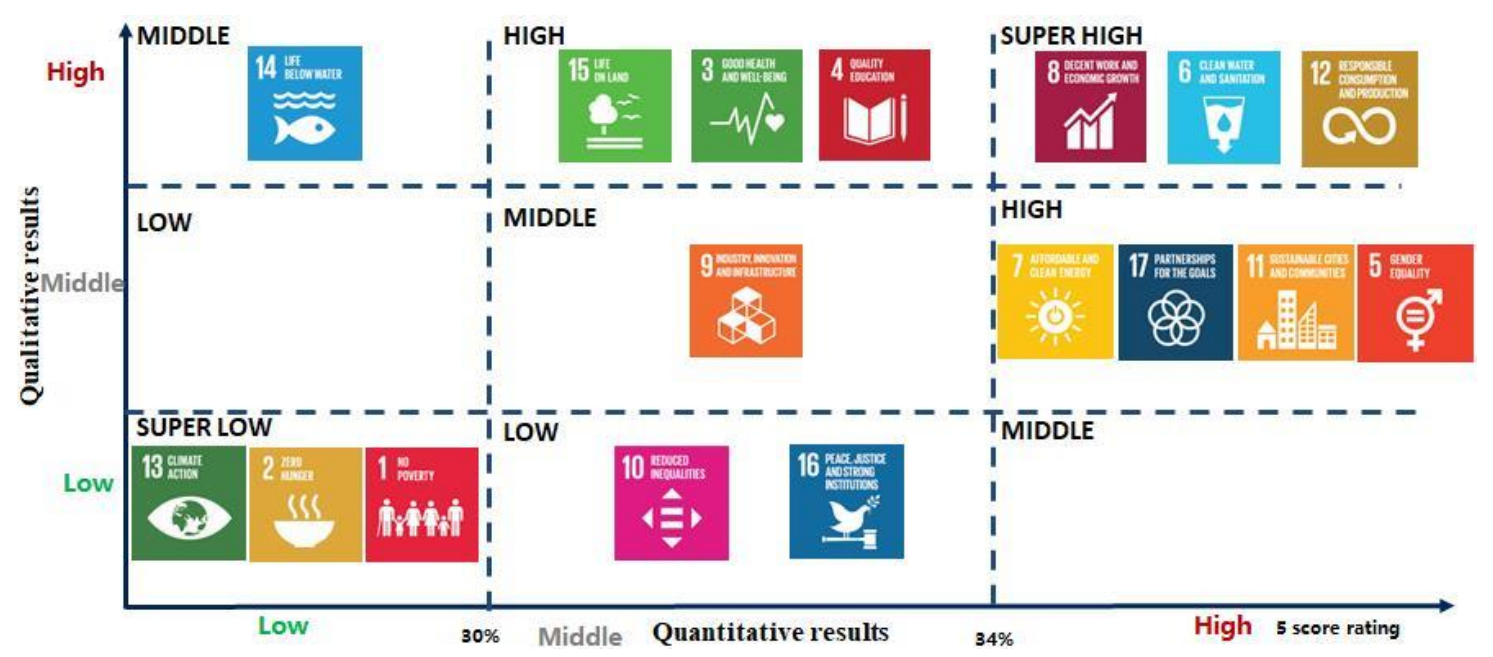

Figure 3. Correlation between 17 SDGs and Chinese Bars in Qualitative and Quantitative Results.

\subsection{Intra-Industry Seminar}

Based on the above study, qualitative and quantitative research and result analysis, the tripartite research group formulated the initial draft of initiatives and guidelines for the bar industry in China and invited relevant industry practitioners and bar managers to hold one seminar in Shanghai on sustainable drinking bars in China. The participants were briefed on the research background, project framework, survey findings, and results, and organized to discuss and obtain their opinions for the next step of the preparation of the final drafts. The content industry seminars were in three parts: 1) To discuss whether the super high, high, medium, super low, and low correlation of each target is reasonable; 2) To discuss at which level each SGD should be placed (Super High, High, Medium, Low, Super Low), according to everyone's relevant experience and cognition in the bar industry; 3 ) To discuss the priority of actions in guidelines (short-term, medium, and long term) and discuss the relevant action results of the intra-industry seminar that were well recorded and selected for the next step of final drafts writing.

\subsection{Publishing "Sustainable Bar Operation Initiatives" and "Operational Sustainable Bar Application Guidelines"}

To think global and act local, the tripartite research group has put forward the "Sustainable Bar Operation Initiatives" (Appendix A) and the "Operational Sustainable Bar Application Guidelines" (Appendix B) to provide action guidelines for the sustainable development of the bar industry. This initiative was taken against the backdrop of sustainable development and the importance of the 2030 Agenda and its SDGs, thereby adhering to corporate social responsibility for sustainable development and grasping the development trend of the Chinese bar industry and the global concept of sustainable 
bars, which is based on the background research, qualitative and quantitative research, analysis of results and discussions within the industry. The initiatives and guidelines contain the details of daily operations. Thus, there is hope to practice the concept of sustainable development to help the bar industry realize a healthier and greener development on a long-term basis while embracing the increasing demand of consumers for catering services and consumption.

\section{Conclusions}

China remains a large alcohol consumption market owing to its economic and social development. Drinking bars are ubiquitous in China, with large market size and variety. The concept of sustainable bars is accepted throughout the world, and many bars operate towards sustainability based on their local characteristics. For the development of society, sustainability and SCP have to play more important roles in the growing drinking bar industry in China.

Given the qualitative research via 15 interviews of drinking bars, the concept of a sustainable bar has also been recognized by bars in China, and several bars have their own practices regarding sustainability or SCP. Bar operators agree on the importance of sustainable bars and are willing to make efforts towards it. The results show that bar owners or managers in China do have awareness of sustainability and SCP and are willing to take more actions and their bars and give suggestions for the whole drinking bar industry in China. In line with the qualitative interview and analyses, the relevance of 17 SDGs with drinking bars in China has been divided into three groups: high, middle, and low. The high relevance group contains SDG3, SDG4, SDG6, SDG8, SDG12, SDG14, and SDG15, which may be more related in the production, consumption, and management of bars in China. The middle relevance group includes SDG5, SDG7, SDG9, SDG11, and SDG17. The low Relevance Group includes SDG1, SDG2, SDG10, SDG13, and SDG16.

According to the quantitative research involving 321 practitioners in drinking bar industry in China from Shanghai, Shenzhen, and Beijing, almost $57.8 \%$ of practitioners think sustainable development is very important for bar industry in China, and $49.8 \%$ of the practitioners often discuss about sustainable development in bar industry. Further, $61.3 \%$ of them demonstrated a very positive attitude towards sustainable development in bar industry. However, $61.5 \%$ of them seldom hear or witness actions for sustainable development of colleagues. This shows that although bar practitioners do agree with the importance of sustainable development and have a basic notion about it, their actions and practices are very limited.

Following the quantitative research and a five-item scoring system, the relevance of 17 SDGs with drinking bars in China has been divided into three groups. The high relevance group contains SDG8, SDG6, SDG7, SDG17, SDG12, SDG11, and SDG5. The middle relevance group involves SDG9, SDG10, SDG16, SDG15, SDG3 and SDG4. The low relevance group includes SDG13, SDG14, SDG2, and SDG1. To compare Figures 1 and 2, SDG6 (Clean water and sanitation), SDG8 (Decent work and economic growth)and SDG12 (Responsible consumption and production) all have been considered highly related and SDG1 (No poverty), SDG2 (Zero hunger) and SDG 13 (Climate action) all have been considered as lowly related. Meanwhile, SDG14 (Life under water) is considered as highly related in qualitative research, it is considered as lowly related in quantitative research.

Based on the results of the qualitative and quantitative research, the relevance of 17 SDGs with drinking bars in China has been grouped into super high (SDG8, SDG6, and SDG12), high (SDG15, SDG3, SDG4, SDG7, SDG17, SDG11, and SDG5), middle (SDG14 and SDG9), low (SDG10 and SDG16), and super low (SDG13, SDG2, and SDG1) in the horizontal and vertical axis.

Based on the results, a workshop for discussion by invited practitioners and operators of drinking bars in China is conducted, and their opinions on the results and 17 SDGs in bars of China are noted and analyzed. The "Sustainable Bar Operation Initiatives" in Appendix A and the "Operational Sustainable Bar Application Guidelines" in Appendix B are drafted and released based on the research results.

This survey has obtained information about the development of bars in China and the response of Chinese bars to sustainable development and the 2030 Agenda. We explored the value of SDGs 
in the bar industry and obtained qualitative and quantitative research results that are relevant to intra-industry discussions, which is of great reference value for the entire industry, academia, and policymakers of governments domestically and globally.

This study has certain limits. China is geographically huge and densely populated with differing level of development. There are numerous bars with various types all over the country. So, research conduct in this study mainly in three big and developed cities (Shanghai, Shenzhen and Beijing) may not represent the whole drinking bar industry in China. The differences among the three cities and different jobs, levels of recognition, and attitudes of bar practitioners should also be considered. On the other hand, there are many political policies, initiatives, and guidelines pertaining to sustainable development and SCP as well as actions in society, not only limited to the 2030 Agenda of UN. Hence, there is a need for a more in-depth, theoretical, and interdisciplinary study in the future.

Author Contributions: Conceptualization, Y.L.; Methodology, Y.L.; Writing-original draft preparation, Y.L.; Project administration, Y.L. All authors have read and agreed to the published version of the manuscript.

Funding: This research was financially supported by Pernod Ricard China. As well as, the author would like to acknowledge the support of the China National Social Science Foundation for the Major Project (Grant No. 17ZDA077), the International Postdoctoral Exchange Programs of China National Postdoctoral Council (CNPC) and the China Postdoctoral Science Foundation (2018 M641307 and 2019 T120076).

Acknowledgments: The author would like to give special thanks to Colleagues from Pernod Ricard China and Kantar China and all the Participants from the Chinese bar industry. The author also would like to acknowledge Professor Xufeng Zhu and Colleagues from the Institute for Sustainable Development Goals (TUSDG) of Tsinghua University and Colleagues from Burson Cohn \& Wolfe (BCW) China.

Conflicts of Interest: The author declares no conflict of interest.

\section{Appendix A. Sustainable Bar Operation Initiatives}

\section{SDG1: No Poverty}

Take steps to operate bars legally and appropriately, provide services and jobs to society, remit taxes to the government, and bring the market to enterprises and companies; bars and the bar industry should care for employees from families with financial difficulties and provide them with assistance; provide employees with good benefits and security; and ensure the legal earning, rights, and interests of its employees.

\section{SDG2: Zero Hunger}

Conserve food, beverages and ingredients in bar operations to reduce waste, and incorporate it into the business model, management, and industry standards; provide internal and industry-wide training, education, tours, and activities to enhance the awareness of relevant issues; organize relevant communications and activities to show consumers the "farm-to-table" process of food and increase their awareness of conservation and environmental protection.

\section{SDG3: Good Health and Well-being}

Encourage customers to adopt healthy lifestyles and moderate drinking for relaxation; strictly comply with relevant food quality and safety laws, regulations, and internal standards; strictly check the quality and safety of mixology ingredients and food materials while strictly managing expiration dates; pay attention to the physical and mental health of employees and provide them with a good working environment and reasonable working hours and tasks; provide shift workers with basic living accommodations, meals and reasonable paid time off, provide employees with corresponding health benefits, security, health checkups and training, and organize group fitness and outdoor activities on a regular basis. 


\section{SDG4: Quality Education}

Provide employees with bar industry professional knowledge and skills training and opportunities for domestic and overseas exchanges; expand employee's horizons and improve their comprehensive occupational capabilities through regional assignments, job rotations and function adjustments; provide employees with professional skill certification (such as Wine \& Spirit Education Trust, WSET), resources, and support for courses, such as occupational development, planning, and management; encourage employees to continue reading and learning to improve their oral communication skills, establish supporting and incentive mechanisms.

\section{SDG5: Gender Equality}

Ensure equality in bar recruitment, operation, management, wages, and job promotions; respect and care for employee's work and life balance, and protect their legal rights and interests; value the physical and mental health of employees and provide them with relevant training, guidance, and support.

\section{SDG6: Clean Water and Sanitation}

Strictly ensure the quality and safety of the source of drinking and cleaning water; use professional water source equipment, conduct regular periodic inspections and maintenance; conserve water resource; separate washing and cleaning areas; create a good environment in business operations; clean and sterilize the business venue, appliances, and tools on a regular basis; comply with health and environmental codes of relevant departments; cooperate on inspections; provide relevant results and schedule corresponding actions regularly; and jointly maintain the cleanliness of neighborhoods and communities. The bar industry should form an industry code of clean water and sanitation to be observed accordingly by all bars, in combination with government-directed clean water and sanitation policies and measures.

\section{SDG7: Affordable and Clean Energy}

Incorporate the concept of energy conservation and clean energy into the planning, décor, operation and management of bars, and optimize business operations to conserve energy and reduce consumption; use more energy-efficient and low-energy electrical appliances, including air conditioners, refrigerators, and ice machines, as well as energy-saving equipment such as LED lighting; reduce the use of high-energy consuming electrical appliances, such as electric blenders and mixers; mix or squeeze food manually, instead; install clean energy equipment such as solar energy equipment and use clean energy as much as the premises allow.

\section{SDG8: Decent Work and Economic Growth}

Ensure legal wages, benefits, and paid time off for employees; provide employees with appropriate meals, accommodations, attire, bonuses, and training support; encourage and support employees to improve their professional skills and personal qualities; encourage and support communication and mutual learning among employees, their families, and enterprises; and jointly improve the professional level and industry image to allow the public to fully understand the bar industry and its development.

\section{SDG9: Industry, Innovation, and Infrastructure}

Use innovation ingredients, recipes, operations and management approaches, technology, and tools and equipment to achieve the development of sustainable bars while constantly improving the operation and service level; adopt methods including innovation contests to encourage industry innovation and support the commercialization and materialization of innovation achievements; collaborate with relevant organizations, scientific research institutions, and producers to further innovate. 


\section{SDG10: Reduced Inequalities}

Respect employees and their occupational development; employ outstanding domestic and international employees to facilitate the exchange of ideas, experience, and technical know-how; invite domestic and international industry experts and practitioners to deliver lectures and provide training to reduce the gap between the industries domestically and internationally.

\section{SDG11: Sustainable Cities and Communities}

Reduce impacts to surrounding neighborhoods and adopt measures such as noise reduction, designated smoking areas, and reducing pollution and emissions in the business operation of bars; communicate and interact with surrounding communities, businesses, and residents to jointly maintain the harmony and development of communities; conduct community communication activities to better understand each other and become closer to create a good co-community environment; work with communities to conduct public welfare activities (such as charity sales), service activities (such as charity sales), service activities (such as neighborhood cleanup, waste sorting, and recycling), and educational activities (such as wine tastings, mixology knowledge sharing and training); provide community residents with benefits.

\section{SDG12: Responsible Consumption and Production}

Bars should consider environmental protection factors of ingredients, such as carbon emissions in the process of production, packaging, and transportation; support environmental protection by reusing wooden delivery boxes; use local and green ingredients and reduce ingredient waste in the business operations; use recyclable and biodegradable materials such as recyclable and biodegradable straws, coasters, and glasses in the operation and daily maintenance processes; reduce or eliminate the use of plastic products such as plastic straws and stirrers; sort and dispose garbage and waste by a purposeful recycling method towards sustainability; promote internal codes within the industry to jointly facilitate sustainable operation and consumption.

\section{SDG13: Climate Action}

Use energy-saving and low-emissions equipment; optimize management and operation processes to conserve energy and reduce emissions; launch relevant initiatives and conduct activities within the industry to enhance awareness; carry out exchanges and mutual learning with domestic and international industry peers; and respond to international initiatives including "The Paris Agreement" to jointly put efforts into the Climate Action.

\section{SDG14: Life Below Water}

Reduce water waste and use water-saving technologies and equipment to recycle and reuse water; reduce the use of chemical cleaning detergent and use environment-friendly detergent and materials; sort garbage and waste by a sustainable recycling purpose and method and do not discharge polluted water or waste to the water source; recycle certain types of waste including empty bottles and corks; set up relevant codes within the industry; recycle waste in collaboration with retailers and recyclers; and communicate with government departments to encourage the establishment of relevant recycling regulations.

\section{SDG15: Life on Land}

Reduce the consumption and waste of ingredients; make full use of ingredients and optimize the production process and resource utilization; reuse and recycle ingredients; bars can plant select ingredients in the operating space, which not only provides fresh ingredients but also reduce the environmental cost of production and make the space greener and more pleasant; sort garbage and waste by a sustainable recycling purpose and method to reduce environmental impact to surrounding areas. 
SDG16: Peace, Justice and Strong Institutions

Maintain public order and security in and around bars during operation hours; remind customers to be safe and drink moderately; make them aware of the risks of drinking and driving, and help them call designated driver services when necessary.

\section{SDG17: Partnerships for the Goals}

Strictly comply with relevant laws and regulations of the government and the industry; establish relevant industry organizations and associations; develop relevant industry standards including waste sorting and recycling codes; communicate and cooperate with government and non-government organizations; carry out exchanges, mutual learning, and cooperation with international peers and groups; positively respond to and participate in the implementation of UN's 2030 Agenda for Sustainable Development and the realization the 17 SDGs.

\section{Appendix B. Operational Sustainable Bar Application Guidelines}

\section{Short Term}

SDG2: Zero Hunger

Reduce and Eliminate Food Waste

Promote the "Empty Plate" concept on tableware and tables in employee cafeterias; assign dedicated personnel to supervise food waste; explain the "farm-to-table" process to consumers and raise their awareness of conservation and environmental protection.

SDG3: Good Health and Well-being

Advocate a Healthy Lifestyle and Drink in Moderation

Communicate to employees and customers that moderate drinking is a part of relaxation after busy work.

Care for Employees' Physical and Psychological Health

Remind and require employees to pay attention to their daily schedules and avoid disruptions due to the operating hours of bars to minimize the negative impact on health; organize annual comprehensive medical examinations in addition to the health certificate examination; organize team sports and fitness activities in spare time.

Strictly Control the Quality and Safety of Food Ingredients

Supply food with safety certifications; standardize food expiration time.

SDG5: Gender Equality

\section{Ensure Gender Equality in Recruitment and on the Job}

Do not make assumptions about performance results based on gender. Do not offer direct privileges to female employees due to their comparative disadvantage in strength, but assist them when they request support. Identify the strengths of each individual on the job. Understand and respect the strengths and disadvantages of each employee and assign appropriate job functions with equal treatment. Care for and encourage all employees regardless of gender; pay attention to their physical and mental development and show appropriate care. 


\section{SDG6: Clean Water and Sanitation}

Ensure the Safety and Sanitation of Water and Drinking Water

Use professional water purification systems. Check and maintain filter units periodically and regularly; on the bar counter, separate the sinks for handwashing and sinks for washing food ingredients.

Ensure Cleanliness and Tidiness of the Bar Environment

Arrange regular (e.g., weekly) thorough cleaning of the entire bar; arrange designated personnel to check the hygienic conditions of each section in the bar and provide feedback to all departments for reference and improvement; clean up used napkins and other trash on guests' table proactively.

\section{SDG7: Affordable and Clean Energy}

\section{Use more Low-Energy Appliances}

Use more energy-efficient air-conditioners, refrigerators, ice machines, and other appliances; use energy-saving lighting; when opening new bars or renovation bars, purchase power-saving models for the high-power-usage appliances, including ice makers that are widely used in the industry to reduce the use and cost of electricity in the long run.

\section{SDG8: Decent Work and Economic Growth}

\section{Guarantee Welfare Benefits}

Provide employees with basic catering, bonuses, and time off; organize professional training regularly; ensure paid time off and paid heath checkups based on relevant laws and regulations; offer career development opportunities and support.

SDG9: Industry, Innovation, and Infrastructure

Innovate Sustainable Cocktail Recipes According to Market Demand

Try a variety of homemade methods to innovate the taste of drinks; develop more improved recipes based on traditional cocktail recipes to meet consumer demands for taste innovation.

\section{SDG11: Sustainable Cities and Communities}

Work with Neighboring Residents and Businesses to Maintain the Community's Environment and Social Harmony

Join organizations such as chambers of commerce to arrange comprehensive activities like free tasting and, if possible, charity events to benefit the community. Carry out communication and mutual assistance with community residents such as cleaning the streets and neighborhood when cleaning the bar; send recyclable waste such as plastic bottles and cardboard boxes to the community recycling personnel through proper garbage classification.

\section{SDG12: Responsible Consumption and Production}

\section{Consider the Sustainability of Raw Ingredients}

Consider the impact of ingredients on the environment and carbon emissions at the production site; choose product supply based on quality grades and ensure that agricultural products with ordinary outlook but of good quality can also be used rather than discarded. 
Use Biodegradable and Recyclable Bar Supplies

Straws could be made from macaroni, sugarcane pulp, PLA polylactic acid, and other biodegradable materials; choose coasters made from recyclable materials, such as old denim, wood chips, rattan, and metal; choose cups made from materials such as coconut shells (old coconut shells can even be used as fuel), ceramic, metal and wood.

Reduce the Use of Coasters, Straws and Reuse Materials

Reduce or refrain from providing coasters and straws. For example, use glasses with stems instead of providing coasters; suppliers can reuse wooden boxes when delivering products to bars.

\section{Classify and Recycle Waste and Reach Industry Consensus}

Undertake daily trash weighing for each department to evaluate and improve the quantity and quality of the food supplies and classify trash by type, purpose, and recycling methods. Reach a consensus within the industry, supervise each other, and cooperate with government policies on waste classification and recycling.

SDG 14: Life Below Water

\section{Reduce Water Waste}

Use high-pressure and professional glassware washers for a more efficient glassware washing. Use environmentally-friendly and energy-saving washers instead of handwashing; operate the glassware washer when it is full. Use ice makers with an energy-saving mode, where the ice made does not melt easily and does not need to be made repeatedly. Recycle water resources, such as watering flowers with fish tank water; advocate for drinking whiskey without ice consumption.

\section{Reduce Waste Pollution and Promote Recycling}

For example, use empty alcohol bottles to make candleholders for use in the bar. Use bottles to hold homemade syrup, cordial, or other stock; wine bottle cords can be re-used for things such as decoration, floor mats, and hooks.

\section{Reduce the Use of Chemicals and Additives}

Reduce the use of chemicals, such as pesticides and farm chemicals in the production of raw ingredients. Choose organic or pesticide-free fruits and vegetables when purchasing raw ingredients.

\section{Use Environmentally-Friendly Detergent or Natural Products as Detergent}

Use the natural oils in fruit peels to make natural or enzyme detergents.

SDG15: Life on Land

Make the Best Use of Raw Ingredients

Fresh fruits can be juiced, and fruit peels can be used as a cocktail garnish. The oil in fruit peels can be used to make natural dishwashing essence or natural enzyme detergent to clean dishes, utensils, and glasses, which is low-cost and environmentally-friendly. Fruit peels and pulp can be dried to make cookies; fruit pulp after juicing can also be used to make fruit pies, porridge, fruit wine, or natural syrups.

\section{Share Kitchen Resources and Make Full Use of Raw Ingredients}

Bars with kitchens can use leftover ingredients and distill its essences, such as making distinctive Gin Tonic with the fragrance of fresh beef, for basil and rosemary, which cannot be mixed in cocktails but can be sent to the kitchen for a garnish or as spices for frying dishes. 
SDG16: Peace, Justice and Strong Institutions

Maintain Order in the Bar

Prevent conflicts, fights, and brawls in bars; remind and advise customers to drink moderately; call driver services for customers.

Maintain Social Order and Public Security

Bar operators should reach a consensus to maintain social order and public security. Consider the impact of bar operations and operation hours on community security and overall social stability, try to increase positive influence, and prevent negative impacts.

SDG17: Partnerships for the Goals

Exchanges and Cooperation within the Industry

Exchange industry knowledge and essential recipes with peer practitioners, create an atmosphere of mutual exchange and learning, establish industry organizations and associations, and jointly realize the sustainable development of bars.

\section{Medium and Long Term}

SDG1: No Poverty

Provide Employment Opportunities and Realize Social Value

The rise and prosperity of the bar industry have created more employment opportunities for society to some extent; it has provided good welfare and guarantee for employees; it has ensured the legal income and rights of employees.

\section{SDG4: Quality Education}

\section{Provide Professional Skills and Knowledge Training to Employees}

Ensure periodic and regular training of service knowledge, wine and spirits knowledge, and mixing skills through tram sharing or guest sharing. Create an atmosphere of language learning through methods such as a language exchange corner, communication skills training, and reward mechanism; encourage employees to keep reading and learning to share insights with the team and customers. Provide employees with resources and financial support for professional certification (e.g., WSET) and additional courses (e.g., online management courses).

Provide Employees with Career Development Opportunities and Support

Bars that are part of a group or chain can provide opportunities for employee career development with assignments to different stores and regions. Communicate with employees to understand their career and learning expectations and make efforts to satisfy through job rotations or functional adjustments.

\section{SDG7: Affordable and Clean Energy}

\section{Use Clean Energy}

Bars with rooftops or outdoor space can use solar power umbrellas, which not only meet customer's needs of using electricity outdoors but also provide convenience for bars (no power strips needed). 
Save Energy by Reducing the Unnecessary Use of Appliances

When creating cocktail recipes, reduce ingredients that require the use of electric mixes and eggbeaters to ensure efficiency; for example, reduce the use of high-foam egg in mixing drinks and encourage the use of the more efficient manual stirring rods; encourage the use of manual tools in squeezing lemon juice.

\section{Adopt Energy and Resources-Saving Bar Counter Designs and Drink Mixing Procedures}

Consider the resource and energy consumption in the design of bars. Design every step reasonably while making drinks, and optimize the mixing procedures. For example, certain mixing procedure requires that the tap should be turned on only once.

\section{SDG8: Decent Work and Economic Growth}

Improve the Internal and External Cultivation of Employees

Improve the professional skills of employees through training; encourage employees through training; encourage employees to visit and observe other bars for reference. Encourage employees to enrich their knowledge and experience through reading and traveling; adopt standard dress codes and styles to improve the sophistication and image of employees.

\section{Improve Social Recognition of the Industry}

Improve public perception of the image of bars by improving the sophistication level of the whole industry. Introduce the expertise and professional skill, as well as the required ability to master ingredients for drink mixing through different platforms (such as variety shows and social media), to give the public a more comprehensive understanding of the industry.

\section{SDG9: Industry, Innovation, and Infrastructure}

\section{Utilize New Technologies and Equipment for Sustainable Drink Mixing}

Utilize new instruments, such as centrifugal machines and distillation apparatus, as well as chemical reactions, including acidification, to explore more possibilities of ingredients that can make the best use of everything while obtaining innovative ingredients for drink mixing. For example, produce transparent syrup by acidifying and decolorizing milk, utilize the cheese obtained after the acidification for other edible purposes, and decolor $\mathrm{Pu}$ 'er Tea after distillation to produce a transparent liquid with the fragrance of tea for drink mixing. Dry the pulp of tomatoes after squeezing to obtain edible garnish to be used in drink mixing.

\section{Use Upgraded Drink Mixing Tools to Improve Efficiency and Reduce Energy Consumption}

Modify the stirrer head of manual stirring rods by utilizing the turbine principles; replace wooden materials with stainless steel to achieve more efficient stirring and facilitate cleaning and storing; use measuring cups produced through modified molds, which has a longer service life as its upper and lower parts are connected, rather than welded together individually.

\section{Innovate Pre-Mixed Cocktail Products}

Develop sustainable cocktail products for bars and in-home mixing through the establishment of innovation labs and other approaches. Develop a sustainable cocktail drinks menu; plan and use existing ingredients appropriately with the aim of zero waste or minimal waste and develop sustainable cocktails menus for customers. 


\section{SDG10: Reduced Inequalities}

Employ more Outstanding Domestic and International Employees with Advanced Skills and Management Experience

Recruit more outstanding domestic and international employees with advanced industry skills, concepts, management experience, and international perspectives. Provide employees with training opportunities, both domestically and internationally. Invite well-known local and international bartenders as guest lecturers; provide foreign employees with help regarding working documents and applications according to government policies.

\section{SDG11: Sustainable Cities and Communities}

Reduce the Impact of Noise and Smoke on the Neighboring Residents through Bar Decoration and Area Planning

Employ prevalent use of sound-proof glass for noise reduction; set the smoking area in non-main streets and control the closing time when organizing outdoor activities.

Benefit Community Residents and Businesses

Provide community residents with benefits, such as discounts or new drink tasting. Share mixology knowledge and industry information within the bar community by guest lecture or master classes. Act as a shared space for the community to exchange information and knowledge.

\section{SDG13: Climate Action}

\section{Enhance Industry Consensus and International Exchanges}

Hold relevant initiatives and activities to raise awareness within the industry; carry out international exchanges and mutual learning with peers; respond to international climate actions, including "The Paris Agreement."

SDG15: Life on Land

Grow-Your-Own/Make-Your-Own Ingredients for Mixing Drinks

Utilize roof terraces or small planters to plant rosemary, basil, and other ingredients that are frequently used in drink mixing as supplements; large-scale chain bars can tap into the source of their supply chain and grow ingredients locally for drink mixing.

SDG17: Partnerships for the Goals

Cooperate with Relevant Departments and Organizations

Cooperate with governments, NGOs, and communities to realize sustainable development together.

\section{Conduct International Exchanges and Cooperation}

Carry out exchanges, mutual learning, and cooperation with international peers and groups; actively respond to and participate in the implementation of the 2030 Agenda for Sustainable Development and SDGs.

\section{References}

1. Li, Y.B.; Zhu, X.F. The 2030 agenda for sustainable development and China's belt and road initiative in Latin America and the Caribbean. Sustainability 2019, 11, 2297. [CrossRef] 
2. Eurostat. Sustainable Development in the European Union, Overview of Progress towards the SDGs in an EU Context. 2017. Available online: https://ec.europa.eu/eurostat/documents/4031688/8461538/KS-01-17796-EN-N.pdf/f9c4e3f9-57eb-4f02-ab7a-42a7ebcf0748 (accessed on 25 September 2018).

3. United Nations. Transforming Our World: The 2030 Agenda for Sustainable Development. 2015. Available online: https://sustainabledevelopment.un.org/post2015/transformingourworld/publication (accessed on 16 July 2019).

4. United Nations Environment Programme (UNEP). Sustainable Consumption and Production: A Handbook for Policymakers; UNEP: Nairobi, Kenya, 2015.

5. United Nations (UN). United Nations Guidelines for Consumer Protection; UN: Geneva, Switersland, 2016.

6. United Nations Environment Programme (UNEP). The 10-Year Framework of Programmes on Sustainable Consumption and Production; UNEP: Nairobi, Kenya, 2017.

7. Ma, Y.G.; Rong, K.; Luo, Y.N.; Wang, Y.; Mangalagui, D.; Thornton, T.F. Value Co-creation for sustainable consumption and production in the sharing economy in China. J. Clean. Prod. 2019, 208, 1148-1158. [CrossRef]

8. United Nations Statistics Division (UNSD). Tier Classification for Global SDG Indicators; UNSD: New York, NY, USA, 2019.

9. Chen, H.M. Sustainable consumption and production in China. In Handbook on Sustainability Transition and Sustainable Peace; Brauch, H.G., Oswald Spring, Ú., Grin, J., Scheffran, J., Eds.; Springer: Berlin/Heidelberg, Germany, 2016; pp. 571-591.

10. Shao, J. Sustainable consumption in China: New trends and research interests. Bus. Strategy Environ. 2019, 28, 1507-1517. [CrossRef]

11. Schroeder, P. Assessing effectiveness of governance approaches for sustainable consumption and production in China. J. Clean. Prod. 2014, 63, 64-73. [CrossRef]

12. Hao, W.; Chen, H.H.; Su, Z.H. China: Alcohol today. Addiction 2005, 6, 737-741.

13. Statista. 2019. Available online: https://www.statista.com/outlook/10000000/117/alcoholic-drinks/china\# market-globalRevenue (accessed on 16 November 2019).

14. Lin, H.; Tavoletti, E. The marketing of Italian wine brands in China: The mainstreaming' approach. Transit. Stud. Rev. 2013, 20, 221-237. [CrossRef]

15. OIV (International Organisation of Vine and Wine). 2019 Statistical Report on World Vitiniculture. 2019. Available online: http://www.oiv.int/public/medias/6782/oiv-2019-statistical-report-on-world-vitiviniculture. pdf (accessed on 16 July 2019).

16. García-Cortijo, M.C.; Villanueva, E.; Castillo, J.S.; Li, Y.B. Wine consumption in China: Profiling the 21st Century Chinese wine consumer. Ciência e Técnica Vitivinícola 2019, 2, 71-83. [CrossRef]

17. Li, Y.B.; Bardaji, I. A new wine superpower? An analysis of the Chinese wine industry. Cah. Agric. 2017, 6, 1-9. [CrossRef]

18. CHYXX. Analysis of China's Bar Industry and Advisory Report for Investment Decision 2018-2024. Available online: https://www.chyxx.com/research/201808/668660.html (accessed on 12 April 2019). (In Chinese).

19. Sgarbi, G. The Sustainable Bar Revolution: Five Secrets from the Bars Championing a New Standard in Cocktails. Theworlds50best. 2018. Available online: https://www.theworlds50best.com/stories/ News/sustainable-bar-revolution-five-secrets-from-bars-championing-new-standard.html (accessed on 20 April 2019).

(C) 2020 by the author. Licensee MDPI, Basel, Switzerland. This article is an open access article distributed under the terms and conditions of the Creative Commons Attribution (CC BY) license (http://creativecommons.org/licenses/by/4.0/). 